\title{
Comparing RADseq and microsatellites to infer complex phylogeographic patterns, a real data informed perspective in the Crucian carp, Carassius carassius, L.
}

Authors: ${ }^{1}$ Daniel L Jeffries, ${ }^{2}$ Gordon H Copp, ${ }^{1}$ Lori Lawson Handley, ${ }^{3} \mathrm{~K}$. Håkan Olsén, ${ }^{4}$ Carl D Sayer, , ${ }^{1}$ Bernd Hänfling

${ }^{1}$ Evolutionary Biology Group, School of Biological, Biomedical and Environmental Sciences, Hardy Building, University of Hull, Hull, HU6 7RX, UK

${ }^{2}$ Salmon \& Freshwater Team, Cefas, Pakefield Road, Lowestoft, Suffolk NR33 OHT, UK, and Department of Life and Environmental Sciences, Faculty of Science and Technology, Bournemouth University, Poole, UK

${ }^{3}$ School of Natural Science, Technology and Environmental Studies, Södertörn University, Alfred Nobels allé 7, Flemingsberg, 14189 Huddinge, Sweden

${ }^{4}$ Environmental Change Research Centre, Department of Geography, University College London, Pearson Building, Gower Street, London, WC1E 6BT, UK

\section{Acknowledgements}

The authors thank the FSBI (www.fsbi.org.uk) and Cefas (Lowestoft, UK) for funding this research. We thank the following landowners, and contributors of fish tissue; Keith Wesley, Ian Patmore and Dave Emson (England), L. Urho (Helsinki, Finland), M. Himberg (Salo, Finland), J. Krekula (Steninge Castle, Uppland, Sweden), B.-M. Josephson and G. Josephson (Styrstad Vicarage, Sweden), G. Hellström (Umeå University, Sweden), K.Ø. Gjelland (NINA, Tromsø, Norway), N. Hellenberg (Gotland Island, Sweden), A. Tuvikene (Center for Limnology, Tartu, Estonia), S.V. Mezhzherin (Kiev, Ukraine), K. Lindström (Kvicksund, Sweden), K.-J. Dahlbom and G. Sundberg (Åland Island, Finland), O. Sandström and M. Andersson (Skutab, Öregrund, Sweden), B. Tengelin (Structor Miljöteknik AB), A. Olsén-Wannefjord (Uppsala, Sweden), Müller Tamás (Godollo, Hungary), András Weiperth (Hungary), Peter D Rask Møller and Henrik Carl (Copenhagen, Denmark), Oksana Stoliar, (Ternopil, Ukraine), Manuel Deinhardt (Jyväskylä, Finland). 


\begin{abstract}
The conservation of threatened species must be underpinned by phylogeographic knowledge in order to be effective. This need is epitomised by the freshwater fish Carassius carassius, which has recently undergone drastic declines across much of its European range. Restriction Site Associated DNA sequencing (RADseq) is being increasingly used for such phylogeographic questions, however RADseq is expensive, and limitations on sample number must be weighed against the benefit of large numbers of markers. Such tradeoffs have predominantly been addressed using simulated data. Here we compare the results generated from microsatellites and RADseq to the phylogeography of $C$. carassius, to add real-data-informed perspectives to this important debate. These datasets, along with data from the mitochondrial cytochrome b gene, agree on broad phylogeographic patterns; showing the existence of two previously unidentified $C$. carassius lineages in Europe. These lineages have been isolated for approximately 2.2-2.3 $\mathrm{M}$ years, and should arguably be considered as separate conservation units. RADseq recovered finer population structure and stronger patterns of IBD than microsatellites, despite including only $17.6 \%$ of samples (38\% of populations and $52 \%$ of samples per population). RADseq was also used along with Approximate Bayesian Computation to show that the postglacial colonisation routes of $C$. carassius differ from the general patterns of freshwater fish in Europe, likely as a result of their distinctive ecology.
\end{abstract}




\section{Introduction}

Phylogeographic studies have revealed that the contemporary distributions of European taxa and their genetic diversity have been largely shaped by the glacial cycles of the Pleistocene epoch, and in particular by range shifts during recolonisation from glacial refugia(Hewitt 1999). In freshwater fishes, the dynamics of recolonisation are tightly linked to the history of river drainage systems(Bianco 1990; Bănărescu 1990, 1992; Bernatchez \& Wilson 1998; Reyjol et al. 2006). For example, watersheds pose a significant barrier to fish dispersal, often resulting in strong genetic structuring across contiguous drainage systems but during glacial melt periods, ephemeral rivers and periglacial lakes can arise, providing opportunities for colonisation(Gibbard et al. 1988) of otherwise isolated drain basins(Grosswald 1980; Arkhipov et al. 1995). These processes have resulted in complicated recolonisation scenarios in Europe, which, in contrast to North America(Bernatchez \& Wilson 1998), appear to possess few general patterns of population structure in European fishes(Costedoat \& Gilles 2009). The lack of obvious European pattern could be explained, at least in part, by the focus of phylogeographic studies on highly mobile, obligatory or facultative lotic species, with more sedentary, lentic species being largely overlooked.

The crucian carp, Carassius carassius (Linnaeus 1758), is native to parts of central, eastern and northern Europe and almost exclusively restricted to lentic ecosystems, including lakes, ponds and river floodplains (Copp 1991; Copp et al. 2008). C. carassius, has recently experienced sharp declines in the number and sizes of populations throughout its native range, leading to some local population extinctions. The reasons for these declines include habitat loss through drought and terrestrialisation in England (Copp 1991; Wheeler 2000; Sayer et al. 2011), acidification (Holopainen \& Oikari 1992), poor water quality in the Danube river catchment (Navodaru et al. 2002), and hybridisation with several non-native species (Copp et al. 2010; Savini et al. 2010; Mezhzherin et al. 2012; Wouters et al. 2012; Rylková et al. 2013). The susceptibility of $C$. carrassius to genetic isolation and bottlenecks is compounded by small population sizes (Hänfling et al. 2005) and low dispersal (Holopainen et al.). Strong geographic structure is therefore likely in this species. Although the threats to $C$. carassius populations are recognised on a regional level (Lusk et al. 2004; Mrakovčić et al. 2007; Wolfram \& Mikschi 2007; Simic, V et al. 2009; Copp \& Sayer 2010), a global conservation strategy is missing. Broad scale phylogeographic data and definition of evolutionary significant units are essential for informing unified conservation efforts for this species. 
Phylogeographic data have traditionally been collected using mitochondrial gene regions and/or nuclear markers such as AFLPs and microsatellites. However, cost and time often limits the number of these nuclear markers used, which can result in low power for addressing phylogeographic questions (Cornuet \& Luikart 1996; Luikart \& Cornuet 2008; Landguth et al. 2012; Peery et al. 2012; Hoban et al. 2013). Single nucleotide polymorphisms (SNPs) are increasingly used in phylogeography for assessments of population structure (for example see Morin et al. 2010; Emerson et al. 2010; Hess et al. 2011; Hauser et al. 2011) which provide several advantages (Morin et al. 2004). One disadvantage of this approach, however, is that bi-allelic SNP loci contain less information than the highly polymorphic AFLPs or microsatellites (Coates et al. 2009). Large numbers of SNPs are consequently needed to provide adequate statistical power. SNP discovery and assay development, which has been costly and slow in the past, has recently been greatly facilitated by Restriction Site-Associated DNA sequencing (RADseq, (Miller et al. 2006)), which enables thousands of orthologous SNP markers to be quickly isolated from non-model organisms. Despite this new opportunity, microsatellites may still be still more informative and/or cost effective in many cases, allowing for wider geographic coverage and sampling of more individuals per population. A comparison of the utility of RADseq-derived SNPs and microsatellites for phylogeographic studies is needed and will contribute to the important debate on whether it is more advantageous to genotype small numbers of highly polymorphic markers in a large number of samples, or tens of thousands of SNP markers in fewer samples. This trade-off has recently been highlighted as among the most important questions in landscape genetics (Epperson et al. 2010; Balkenhol \& Landguth 2011).

The optimal phylogeographic study design depends heavily on the properties of the study system; in particular the strength of population structure (i.e. $F_{\mathrm{ST}}$ ). In $C$. carassius we expect population structure to be strong and driven by isolation by distance (IBD). If this is so, then patchy geographic sampling along the IBD gradient could result in falsely identified distinct lineages (Schwartz \& McKelvey 2009). We would, therefore, expect the number of populations sampled and their geographic uniformity to be more important than number of loci, or number of samples per population in this study.

In the present study, we use a combination of mitochondrial DNA (mtDNA), microsatellites and genome-wide single nucleotide polymorphisms (SNPs) obtained from RADseq in order to: 1) produce a range wide phylogeography for $C$. carassius as a basis for Europe-wide conservation strategies, 2) test competing scenarios that have potentially contributed to the contemporary distribution of the species, and 3) compare the power of microsatellites and RADseq based 
population structure analyses, in the context of the first two objectives. In this third aim, we add perspectives from real biological data to a topic that has almost exclusively been addressed using simulated datasets (but see (Coates et al. 2009; Hess et al. 2011). Specifically we ask, whether the benefits gained by the high numbers of markers obtained from RADseq outweigh the potential loss of power associated by the reduction in the number of samples.

\section{Methods}

\section{Sample collection and DNA extraction}

We collected 848 C. carassius tissue samples from 49 populations across the species' distribution in central and northern Europe (Table 1, Figure 1). Sample sizes ranged from $n=4$ to $n=37$, with a mean of $n=17$ (Table 1). Fish were anaesthetised by a UK Home Office (UKHO) personal license holder (GHC) in a $1 \mathrm{~mL} \mathrm{~L}^{-1}$ bath of 2-phenoxyethanol prior to collection of a $1 \mathrm{~cm}^{2}$ tissue sample from the lower-caudal fin, and wounds treated with a mixture of adhesive powder (Orahesive) and antibiotic (Cicatrin)(Moore et al. 1990). Tissue samples were immediately placed in $\geq 95 \%$ ethanol, and stored at $-20{ }^{\circ} \mathrm{C}$. DNA was extracted from 2-4 $\mathrm{mm}^{2}$ of each tissue sample using either the Gentra Puregene DNA isolation kit or the DNeasy DNA purification kit (both Qiagen, Hilden, Germany). For the RADseq library, DNA was quantified using the Quant-iT ${ }^{\mathrm{TM}}$ PicoGreen ${ }^{\circledR}$ dsDNA Assay kit (Invitrogen) and normalised to concentrations $\geq 50 \mathrm{ng} \mathrm{ml}^{-1}$. Gel electrophoresis was then used to check that DNA extractions contained high molecular weight DNA.

\section{Molecular markers and methods}

Three types of molecular markers were used in the study. Mitochondrial DNA sequencing was used to identify highly distinct lineages and to date the divergence between them through phylogenetic analysis. Two sets of nuclear markers; microsatellites and RADseq-derived SNPs were used to investigate more recent and complex structure in a population genetics framework and to compare the relative power of each marker to do so. 
bioRxiv preprint doi: https://doi.org/10.1101/025973; this version posted September 2, 2015. The copyright holder for this preprint (which was not certified by peer review) is the author/funder. All rights reserved. No reuse allowed without permission.

Table 1. Location, number, genetic marker sampled, and accession numbers of samples and sequences used in the present study for microsatellite and mitochondrial DNA analyses. mtDNA sequence accession numbers can be found in Supplementary table 5 .

\begin{tabular}{|c|c|c|c|c|c|c|c|c|}
\hline \multirow{2}{*}{ Code } & \multirow{2}{*}{ Location } & \multirow{2}{*}{ Country } & \multirow{2}{*}{ Drainage } & \multicolumn{2}{|c|}{ Coordinates } & \multirow{2}{*}{$\begin{array}{l}\text { Microsatellites } \\
\text { (n) }\end{array}$} & \multirow{2}{*}{$\begin{array}{l}\text { mtDNA } \\
\text { (n) }\end{array}$} & \multirow{2}{*}{$\begin{array}{l}\text { RAD-seq } \\
\text { (n) }\end{array}$} \\
\hline & & & & lat & long & & & \\
\hline GBR1 & London & U.K. & U.K & 51.5 & 0.13 & 9 & & \\
\hline GBR2 & Reading & U.K. & U.K & 51.45 & -0.97 & 4 & & \\
\hline GBR3 & Norfolk & U.K. & U.K & 52.86 & 1.16 & 7 & & \\
\hline GBR4 & Norfolk & U.K. & U.K & 52.77 & 0.75 & 27 & & 9 \\
\hline GBR5 & Norfolk & U.K. & U.K & 52.77 & 0.76 & 14 & & \\
\hline GBR6 & Norfolk & U.K. & U.K & 52.54 & 0.93 & 29 & 3 & \\
\hline GBR7 & Norfolk & U.K. & U.K & 52.9 & 1.15 & 24 & 1 & 10 \\
\hline GBR8 & Hertfordshire & U.K. & U.K & 52.89 & 1.1 & 37 & 3 & 9 \\
\hline GBR9 & Norfolk & U.K. & U.K & 52.8 & 1.1 & 27 & & \\
\hline GBR10 & Norfolk & U.K. & U.K & 52.89 & 1.1 & 14 & & \\
\hline GBR11 & Norfolk & U.K. & U.K & 52.92 & 1.16 & 20 & & \\
\hline BEL1 & Bokrijk & Belgium & Scheldt River & 50.95 & 5.41 & 13 & 1 & \\
\hline BEL2 & Meer van Weerde & Belgium & Scheldt River & 50.97 & 4.48 & 12 & & \\
\hline BEL3 & Meer van Weerde & Belgium & Scheldt River & 50.97 & 4.48 & 8 & & \\
\hline GER1* & Kruegersee & Germany & Elbe River & 52.03 & 11.97 & & 3 & \\
\hline GER2 & Münster & Germany & Rhine River & 51.89 & 7.56 & 21 & 3 & \\
\hline GER3 & Bergheim & Germany & Danube River & 48.73 & 11.03 & 9 & 3 & \\
\hline GER4 & Bergheim & Germany & Danube River & 48.73 & 11.03 & 8 & 3 & \\
\hline CZE1 & Lužnice & Czech Republic & Danube River & 48.88 & 14.89 & 9 & 3 & \\
\hline POL1 & Sarnowo & Poland & Vistula River & 52.93 & 19.36 & 33 & & \\
\hline POL2 & Kikót-Wies & Poland & Vistula River & 52.9 & 19.12 & 34 & & \\
\hline POL3 & Tupadly & Poland & Vistula River & 52.74 & 19.3 & 17 & & 10 \\
\hline POL4 & Orzysz & Poland & Vistula River & 53.83 & 22.02 & 13 & 3 & 10 \\
\hline EST1 & Tartu & Estonia & Baltic Sea & 58.39 & 26.72 & 5 & 3 & \\
\hline EST2 & Vehendi & Estonia & Baltic Sea & 58.39 & 26.72 & 5 & & \\
\hline RUS4* & Velikaya river & Russia & Baltic Sea & 55.9 & 30.25 & 29 & 3 & \\
\hline FIN1 & Joensuu & Finland & Baltic Sea & 62.68 & 29.68 & 32 & 3 & \\
\hline FIN2 & Helsinki & Finland & Baltic Sea & 60.36 & 25.33 & 32 & & \\
\hline FIN3 & Jyväskylä & Finland & Baltic Sea & 62.26 & 25.76 & 37 & 3 & 10 \\
\hline FIN4 & Oulu & Finland & Baltic Sea & 65.01 & 25.47 & 7 & 3 & 8 \\
\hline FIN5 & Salo & Finalnd & Baltic Sea & 60.37 & 23.1 & 10 & 3 & \\
\hline SWE1 & Grānbrydammen & Sweden & Baltic Sea & 59.87 & 17.67 & 25 & & \\
\hline SWE2 & Stordammen & Sweden & Baltic Sea & 59.8 & 17.71 & 21 & 3 & 10 \\
\hline SWE3 & Östhammar & Sweden & Baltic Sea & 60.26 & 18.38 & 27 & 3 & \\
\hline SWE4 & Umeå & Sweden & Baltic Sea & 63.71 & 20.41 & 9 & 3 & \\
\hline SWE5 & Kvicksund & Sweden & Baltic Sea & 59.45 & 16.32 & 9 & & \\
\hline SWE6 & Åland Island & Sweden & Baltic Sea & 60.36 & 19.85 & 8 & 3 & \\
\hline SWE7 & Grillby & Sweden & Baltic Sea & 59.64 & 17.37 & 10 & & \\
\hline SWE8 & Skabersjo & Sweden & Baltic Sea & 55.55 & 13.15 & 19 & 3 & 10 \\
\hline SWE9 & Märsta & Sweden & Baltic Sea & 59.6 & 17.8 & 31 & 3 & \\
\hline SWE10 & Norrköping & Sweden & Baltic Sea & 58.56 & 16.27 & 29 & & 9 \\
\hline SWE11 & Gotland Island & Sweden & Baltic Sea & 57.85 & 18.79 & 11 & 3 & \\
\hline NOR1 & Oslo & Norway & North Sea & 60.05 & 9.94 & & 2 & \\
\hline NOR2 & Troms $\varnothing$ & Norway & North Sea & 69.65 & 18.95 & 16 & & 9 \\
\hline BLS & - & Belarus & Dnieper & 52.47 & 30.52 & 7 & 1 & \\
\hline RUS1 & Proran Lake & Russia & Don River & 47.46 & 40.47 & 10 & 3 & 9 \\
\hline DEN1 & Copenhagan & Denmark & Baltic Sea & 60.21 & 17.79 & 12 & & 10 \\
\hline DEN2 & Pederstrup & Denmark & Baltic Sea & 55.77 & 12.55 & 14 & & 8 \\
\hline DEN3 & Gammel Holte & Denmark & Baltic Sea & 56 & 12.5 & 14 & & \\
\hline DEN4 & Bornholm Island & Denmark & Baltic Sea & 55.17 & 14.86 & & & 5 \\
\hline SWE12 & Osterbybruk & Sweden & Baltic Sea & 55.73 & 12.34 & 14 & & 9 \\
\hline SWE14 & Stockholm & Sweden & Baltic Sea & 59.66 & 18.95 & 16 & & 9 \\
\hline RUS2* & Karma & Russia & Volga River & 52.9 & 58.4 & & 2 & \\
\hline RUS3* & Saygach'yedake & Russia & Volga River & 47.5 & 48.5 & & 4 & \\
\hline HUN1 & Gödöllő & Hungary & Danube River & 47.61 & 19.36 & & 2 & \\
\hline HUN2 & Vörösmocsár & Hungary & Danube River & 46.49 & 19.17 & & & 6 \\
\hline Total & & & & & & 848 & 79 & 154 \\
\hline
\end{tabular}


(Table 1 continued)

\begin{tabular}{lllll}
\multicolumn{2}{l}{ Genbank mtDNA sequences } & & & \\
Code & Reference & Country & Drainage & Accession \\
\hline GER6 & Kalous et al. (2007) & Germany & Baltic sea & DQ399917 \\
GER6 & Kalous et al. (2007) & Germany & Baltic sea & DQ399918 \\
GER6 & Kalous et al. (2007) & Germany & Baltic sea & DQ399919 \\
GER7 & Rylková et al. (2013) & Germany & Hunte River & JN412540 \\
GER7 & Rylková et al. (2013) & Germany & Hunte River & JN412541 \\
GER7 & Rylková et al. (2013) & Germany & Hunte River & JN412542 \\
GER7 & Rylková et al. (2013) & Germany & Hunte River & JN412543 \\
GER8* & Rylková et al. (2013) & Germany & Lahn River & JN412537 \\
GER8* & Rylková et al. (2013) & Germany & Lahn River & JN412538 \\
CZE2 & Rylková et al. (2013) & Czech Republic & Elbe drainage & GU991399 \\
AUS1 & Rylková et al. (2013) & Austria & Danube river & JN412533 \\
AUS1 & Rylková et al. (2013) & Austria & Danube river & JN412534 \\
AUS2 & Rylková et al. (2013) & Austria & Danube river & JN412535 \\
AUS3 & Rylková et al. (2013) & Austria & Danube river & JN412536 \\
GBR12 & Rylková et al. (2013) & U.k. & U.K & JN412539 \\
GBR12 & Kalous et al. (2012) & U.K. & U.K & GU991400 \\
SWE15 & Rylková et al. (2013) & Sweden & Baltic sea & JN412545 \\
SWE16 & Rylková et al. (2013) & Sweden & Baltic sea & JN412544 \\
& & & & \\
† Also present & & & & \\
* Location on & Map (Fig. 1.a) is approximate & &
\end{tabular}

\section{Mitochondrial DNA amplification}

A total of 82 C. carassius individuals, randomly chosen from a subset of 30 populations, which were chosen to represent all major catchment areas and the widest possible geographic range (min. $\mathrm{n}=1$, max. $\mathrm{n}=4$, mean $\mathrm{n}=2.7$ ), were sequenced at the cytochrome $\mathrm{b}($ cytb) gene (Table 1$)$. PCR reactions were carried out following the protocol in Takada et al. (2010) using the forward and reverse primers L14736-Glu and H15923-Thru on an Applied Biosciences® Veriti Thermal Cycler. PCR products were sequenced in both directions on an ABI3700 by Macrogen Europe. The forward and reverse $c y t \mathrm{~b}$ sequence reads were aligned using a GenBank sequence from the UK (accession no. JN412539, Table 1) as a reference and ambiguous nucleotides were manually edited using CodonCode aligner v.2.0.6 (CodonCode Corporation).

\section{Microsatellite amplification}

All 848 C. carassius samples were genotyped at 13 microsatellite loci, which were originally designed for use in Carassius auratus, or Cyprinus carpio and cross amplify in C. carassius (Supplementary table 1). Six of these loci were chosen for their species diagnostic properties, allowing us to ensure that all samples used in the present study were $C$. carassius and not one of the closely-related introduced species (C. carpio, C. auratus, or Carassius gibelio) or their hybrids (see Supplementary text for full details of species identification and hybrid detection). Microsatellites 
were amplified in three multiplex PCR reactions, using the Qiagen multiplex PCR mix with manufacturer's recommended reagent concentrations, including Q solution and $1 \mu$ l of template DNA. Primer concentrations for each locus are provided in Supplementary table 1 and PCRs were performed on an Applied Biosciences ${ }^{\circledR}$ Veriti Thermal Cycler. The annealing temperature used was $54^{\circ} \mathrm{C}$ for all reactions, and all other PCR cycling parameters were set to Qiagen multiplex kit recommended values. PCR products were run on a Beckman Coulter CEQ 8000 genome analyser using a 400 bp size standard and microsatellite alleles scored using the Beckman Coulter CEQ8000 software.

\section{RADseq}

A total of 149 individuals (16 populations, $\min . n=8$, max. $n=10$, mean $n=8.9$ ), identified as pure $C$. carassius with the diagnostic microsatellites, were used in the RADseq (Table 1). These samples were chosen to represent a wide geographic range and all major phylogeographic clusters identified using the microsatellite data. These samples were split across 13 libraries prepared at Edinburgh Genomics (University of Edinburgh, UK) according to the protocol in Davey et al.(2012) using the enzyme $S b f 1$. Libraries were then sequenced across five lanes of two Illumina HiSeq 2000 flowcells (Edinburgh Genomics).

\section{Data analyses}

\section{Phylogenetic analysis of mtDNA}

In addition to the 82 sequenced samples, we retrieved 18 published $C$. carassius cytb sequences from GenBank which were validated through cross checking with their original publications (Table 1). Sequence alignment was performed in MEGA6 (Tamura et al. 2013) using default settings, and DNAsp v.5.0 (Librado \& Rozas 2009) was used to calculate sequence divergence and to identify haplotypes. 


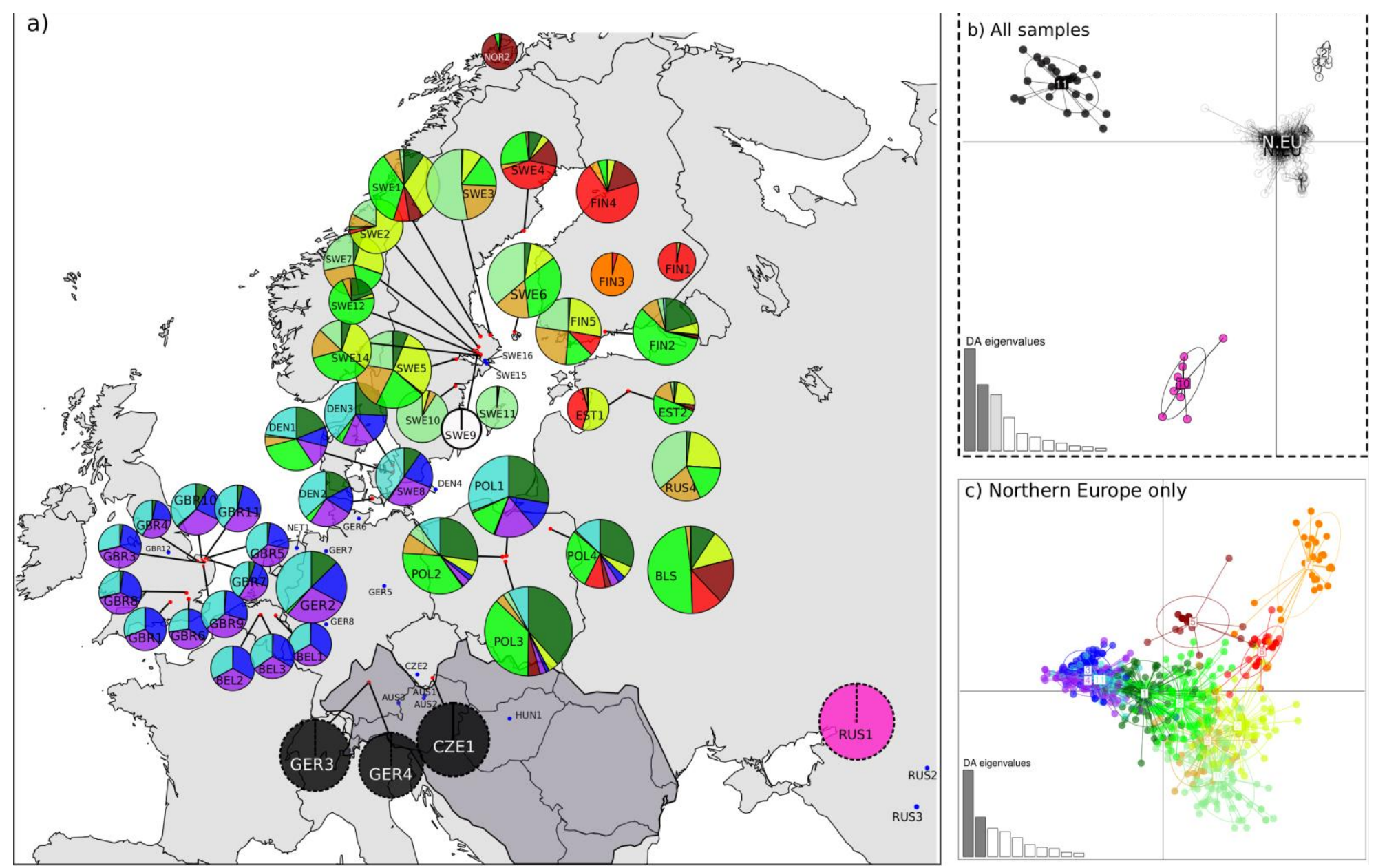

Figure 1. Population structure of C. carassius in Europe. a) Sampling locations (sites sampled with nuclear and mtDNA markers $=$ red dots, $\mathrm{mtDNA}$ only $=$ blue dots) and population cluster memberships from DAPC analysis. Pie chart size corresponds to microsatellite allelic richness. Pie chart colours for Danubian populations and RUS1 correspond to clusters in the broad scale DAPC analysis b) and for all northern European populations colours correspond to clusters in the northern European DAPC analysis (mtDNA lineage 1 only) c). The Danube river catchment is shaded dark grey. 
Haplotypes were exported to BEAST v.1.7.5 (Drummond et al. 2012) for phylogenetic analyses in order to identify the major phylogenetic lineages within European $C$. carassius. The splits between the major phylogenetic clades were then dated using a relaxed molecular clock method in BEAST. The widely-used Dowling et al. (2002)_cyprinid cytb divergence rate of $1.05 \%$ pairwise sequence divergence / MY was used after converting to a per lineage value of 0.0053 mutations/site/MY for use in BEAST. Initial analyses using the GTR (Tavaré 1986) substitution model yielded multiple parameters with low estimated summary statistic (ESS) values $(<100)$, therefore the less complex HKY (Hasegawa et al. 1985) substitution model, which had ESS values $>200$ for all parameters, was used. We used a 'coalescent: constant size' tree prior, which assumes an unknown but constant population size backwards in time, as recommended for intraspecific phylogenies (BEAST Tutorial - Tree priors and dating). MCMC chain lengths were 1 x 10 $10^{7}$ with samples taken every 1000 iterations. A gamma site heterogeneity model was used, with the default of four categories. Substitution rates, rate heterogeneity and base frequencies were unlinked between each codon position to allow substitution rate to vary between them. Default values were used for all other parameters and priors.

\section{Population structure and diversity analyses using microsatellites}

Allele dropout and null alleles in the microsatellite data were tested using Microchecker (Van Oosterhout et al. 2004). FSTAT v. 2.9.3.2 (Goudet 2001) was then used to check for linkage disequilibrium (LD) between loci (using 10,000 permutations), deviations from Hardy-Weinberg equilibrium (HWE) within populations (126500 permutations) and for all population genetic summary statistics. Genetic diversity within populations was estimated using Nei's estimator of gene diversity $\left(H_{\circ}\right)$ (Nei 1987) and Allelic richness $\left(A_{\mathrm{r}}\right)$, which was standardised to the smallest sample size ( $(\mathrm{n}=5)$ using rarefaction (Petit et al. 1998). Pairwise $F_{\text {sт }}$ values were calculated according to (Weir \& Cockerham 1984) and 23520 permutations and sequential Bonferroni correction were used to test for significance of $F_{\text {sт. }}$.

IBD was investigated using a Mantel test in the adegenet v1.6(Jombart \& Ahmed 2011) package in R v3.0.1(R Core Team 2013). We then tested for an association between $A_{r}$ and longitude and latitude, which is predicted under a stepping-stone colonisation model (Ramachandran et al. 2005; Simon et al. 2014), using linear regression analysis in R. 
Population structure was then further examined using Discriminant Analyses of Principal Components (DAPC) also in adegenet (DAPC, see Supplementary text and Jombart et al. 2010 for more details). In preliminary DAPC analysis using all 49 C. carassius populations, Sweden (SWE9) was found to be so genetically distinct from the rest of the data set that it masked the variation between the other populations. This population was therefore omitted from further DAPC analyses. To infer the appropriate number of genetic clusters in the data was, we used Bayesian Information Criteria (BIC) scores, in all cases choosing lowest number of genetic clusters from the range suggested. Spline interpolation(Hazewinkel 1994) was then used to identify the appropriate number of principal components to use in the subsequent discriminant analysis.

\section{RADseq data filtering and population structure analysis}

The quality of the RADseq raw read data was examined using FastQC(Andrews 2010), the dataset was then cleaned, processed and SNPs were called using the Stacks pipeline(Catchen et al. 2013). One SNP per RAD locus was used and, SNPs were only retained if they were present in at least 17 out of the 19 populations in the study, which allows for mutations in restriction sites that may cause loci to dropout in certain lineages. Finally, we filtered out loci which had a heterozygosity of $>0.5$ in one or more populations in order to control for the possibility of erroneously merging ohnologs resulting from the multiple genome duplications that have occurred the Cyprinus and Carassius genera (Henkel et al. 2012; Xu et al. 2014). The resulting refined SNP set was then used in subsequent phylogeographic analyses. The adegenet R package was used to calculate $H_{\circ}$ and pairwise $F_{\mathrm{sT}}$, test for IBD and infer genetic clusters using DAPC.

\section{Reconstructing postglacial colonisation routes in Europe}

DIYABC (Cornuet et al. 2014) was used to reconstruct the most likely $C$. carassius recolonisation routes through Europe after the last glacial maximum. Analyses were performed on 1000 randomlyselected SNP loci from the full RAD-seq dataset were used, as microsatellite loci are likely to be affected by homoplasy over the time scales used here (Morin et al. 2004). The reduced dataset was first analysed with DAPC to confirm that it produced the same structure as the full dataset. Then datasets of expected summary statistics were simulated for a number of scenarios (i.e. a specific population tree topology, together with the parameter prior distributions that are associated with it). These simulated datasets represent the theoretical expectation under each scenario, and are compared to the same summary statistics calculated from the observed data to identify the most likely of the specified scenarios. In DIYABC, two methods of comparison between simulated and observed datasets are used; logistic regression and "direct approach", the latter method identifies the 
scenario that produces the largest proportion of the $n$ number of closest scenarios to the observed, where $n$ is specified by the user. The goodness-of-fit of scenarios was also assessed using the model checking function implemented in DIYABC (Cornuet et al. 2014).

To reduce the number and complexity of possible scenarios, we split DIYABC analysis into three stages (Table 2). In stage 1, we tested 11 broad scale scenarios (Scenarios 1 -11, Supplementary Figure 1), in which populations were grouped into three pools; Pool 1 - all northern European populations (npops $=17, n=155)$, Pool $2-$ Don population (npops $=1, n=9$ ), Pool $3-$ Danubian population (npops $=1, n=6$ ). Both population pooling and scenarios were chosen on the basis of the broad phylogeographic structure identified in the mtDNA and RAD-seq population structure analysis (see Results). We tested the likelihood of these 11 scenarios, simulating one million summary-statistic datasets per scenario, for comparison to the real dataset.

In the second and third stages, we performed a finer scale analysis, focussing on the 17 northern European populations alone. Populations were again pooled on the basis of both population structure and geography, in order to reduce scenario complexity (Table 2). In stage 2 we tested five scenarios (Scenarios 12-16. Supplementary Figure 2a), with no bottlenecks included, which represented the major topological variants that were most likely, given population structure results from DAPC. We then identified the most likely of these scenarios in DIYABC and took this forward into the final stage of the analysis where we tested 6 multiple bottleneck combinations (Supplementary Figure 2b) around this scenario. This three stage approach allowed us to systematically build a complex scenario for the European colonisation of C. carassius. Finally, we used the posterior distributions of the time parameters from the scenario identified as most likely in stages one and three to estimate times of the major lineage splits in European C. carassius. 
bioRxiv preprint doi: https://doi.org/10.1101/025973; this version posted September 2, 2015. The copyright holder for this preprint (which was not certified by peer review) is the author/funder. All rights reserved. No reuse allowed without permission.

Table 2. Population pools, parameter priors used and posterior parameter values inferred in the three stages of DIYABC analysis.

\begin{tabular}{|c|c|c|c|c|c|c|}
\hline $\begin{array}{l}\text { Analysis } \\
\text { stage }\end{array}$ & Population Pools & $\begin{array}{l}\text { Scenarios } \\
\text { tested }\end{array}$ & Parameter priors & $\begin{array}{l}\text { Most } \\
\text { likely } \\
\text { Scenario }\end{array}$ & $\begin{array}{l}\text { Media } \\
\text { distrib } \\
\text { likely s }\end{array}$ & $\begin{array}{l}\text { f posterior } \\
\text { ions of most } \\
\text { nario }\end{array}$ \\
\hline 1 & $\begin{array}{r}\text { Pool 1 - GBR4, GBR7, } \\
\text { GBR8, DEN1, DEN2, DEN3, } \\
\text { FIN3, FIN4, POL3, POL4, } \\
\text { SWE2, SWE8, SWE9, } \\
\text { SWE10, SWE12, SWE14, } \\
\text { NOR2 } \\
\text { Pool 2 - RUS1 } \\
\text { Pool 3 - HUN2 }\end{array}$ & $1-11$ & $\begin{array}{r}\mathrm{N} 1=10 \mathrm{E}+03-500 \mathrm{E}+03 \\
\mathrm{Nb} 1=10-100 \mathrm{E}+03 \\
\mathrm{~N} 2=100-100 \mathrm{E}+03 \\
\mathrm{~N} 3=100-200 \mathrm{E}+03 \\
\mathrm{t} 1=1 \mathrm{E}+03-1 \mathrm{E}+06 \text { gens } \\
\mathrm{t} 2=1 \mathrm{E}+03-3 \mathrm{E}+06 \text { gens } \\
\mathrm{ra}=0.001-0.999 \\
\mathrm{rb}=0.001-0.999 \\
\mathrm{rc}=0.001-0.999 \\
\mathrm{db}=10-10 \mathrm{E}+03 \text { gens } \\
\end{array}$ & 9 & $\begin{array}{l}\mathrm{N} 2= \\
\mathrm{N} 3= \\
\mathrm{t} 1= \\
\mathrm{db}= \\
\mathrm{t} 2=\end{array}$ & $\begin{array}{l}3.47 \mathrm{E}+04 \\
2.37 \mathrm{E}+04 \\
\\
7.49 \mathrm{E}+04 \\
1.40 \mathrm{E}+05 \\
1.35 \mathrm{E}+05 \\
4.46 \mathrm{E}+03 \\
\\
1.09 \mathrm{E}+06\end{array}$ \\
\hline 2 & $\begin{array}{r}\text { Pool } 1 \text { - GBR4, GBR7, } \\
\text { GBR8 } \\
\text { Pool } 2 \text { - DEN1, DEN2, } \\
\text { DEN3 } \\
\text { Pool } 3 \text { - FIN3, FIN4 }\end{array}$ & $12-16$ & $\begin{array}{r}\mathrm{N} 1=10-4 \mathrm{E}+03 \\
\mathrm{~N} 2=10-10 \mathrm{E}+03 \\
\mathrm{~N} 3=10-20 \mathrm{E}+03 \\
\mathrm{~N} 4=10-50 \mathrm{E}+03 \\
\mathrm{~N} 5=10-20 \mathrm{E}+03 \\
\mathrm{~N} 6=10-400 \\
\mathrm{t} 1=100-10 \mathrm{E}+03 \text { gens } \\
\mathrm{t} 1 \mathrm{a}=100-10 \mathrm{E}+03 \text { gens } \\
\mathrm{t} 2=100-10 \mathrm{E}+03 \\
\mathrm{t} 2 \mathrm{a}=100-5 \mathrm{E}+03 \text { gens } \\
\mathrm{t} 2 \mathrm{~b}=500-20 \mathrm{E}+03 \text { gens } \\
\mathrm{t} 2 \mathrm{c}=100-10 \mathrm{E}+03 \text { gens } \\
\mathrm{t} 2 \mathrm{~d}=100-10 \mathrm{E}+03 \text { gens } \\
\mathrm{t} 3=500-20 \mathrm{E}+03 \text { gens } \\
\mathrm{t} 3 \mathrm{c}=100-10 \mathrm{E}+03 \text { gens } \\
\mathrm{t} 3 \mathrm{~d}=100-10 \mathrm{E}+03 \text { gens } \\
\mathrm{t} 4=500-20 \mathrm{E}+03 \text { gens } \\
\mathrm{ra}=0.001-0.999 \\
\mathrm{rb}=0.001-0.999\end{array}$ & 14 & $\begin{array}{l}\text { N1 }= \\
\text { N2 }= \\
\text { N3 = } \\
\text { N4 }= \\
\text { N5 = } \\
\text { N6 }= \\
\text { t1 = } \\
\text { t1a }=\end{array}$ & $\begin{array}{l}3.67 \mathrm{E}+03 \\
7.52 \mathrm{E}+03 \\
1.74 \mathrm{E}+04 \\
1.94 \mathrm{E}+04 \\
1.18 \mathrm{E}+04 \\
\\
2.10 \mathrm{E}+02 \\
6.79 \mathrm{E}+03 \\
2.51 \mathrm{E}+03\end{array}$ \\
\hline 3 & $\begin{array}{r}\text { Pool } 4 \text { - POL3, POL4 } \\
\text { Pool } 5 \text { - SWE2, SWE8, } \\
\text { SWE9, SWE10, SWE12, } \\
\text { SWE14 } \\
\text { Pool } 6 \text { - NOR2 }\end{array}$ & $14 a-14 f$ & $\begin{array}{r}\mathrm{N} 1=10-4 \mathrm{E}+03 \\
\mathrm{Nb} 1=10-10 \mathrm{E}+03 \\
\mathrm{~N} 2=10-10 \mathrm{E}+03 \\
\mathrm{~N} 3=10-20 \mathrm{E}+03 \\
\mathrm{Nb3}=10-10 \mathrm{E}+03 \\
\mathrm{~N} 4=10-50 \mathrm{E}+03 \\
\mathrm{~N} 5=10-20 \mathrm{E}+03 \\
\mathrm{~N} 6=10-400 \\
\mathrm{Nb6}=10-10 \mathrm{E}+03 \\
\mathrm{t} 1=100-10 \mathrm{E}+03 \text { gens } \\
\mathrm{t} 1 \mathrm{a}=100-10 \mathrm{E}+03 \text { gens } \\
\\
\mathrm{t} 2 \mathrm{~d}=100-10 \mathrm{E}+03 \text { gens } \\
\mathrm{t} 3 \mathrm{~d}=100-10 \mathrm{E}+03 \text { gens } \\
\mathrm{t} 4=500-20 \mathrm{E}+03 \text { gens } \\
\mathrm{rb}=0.001-0.999 \\
\mathrm{da}=10-10 \mathrm{E}+03 \text { gens } \\
\mathrm{db}=10-10 \mathrm{E}+03 \text { gens } \\
\mathrm{dc}=10-10 \mathrm{E}+03 \text { gens } \\
\mathrm{dd}=10-10 \mathrm{E}+03 \text { gens } \\
\mathrm{de}=10-10 \mathrm{E}+03 \text { gens }\end{array}$ & $14 d$ & $\begin{array}{l}\mathrm{N} 1= \\
\mathrm{Nb} 1= \\
\mathrm{N} 2= \\
\mathrm{N} 3= \\
\mathrm{N} 4= \\
\mathrm{N} 5= \\
\mathrm{N} 6= \\
\mathrm{t} 1=\end{array}$ & $\begin{array}{l}2.39 \mathrm{E}+03 \\
9.35 \mathrm{E}+02 \\
8.14 \mathrm{E}+03 \\
9.36 \mathrm{E}+03 \\
\\
1.70 \mathrm{E}+04 \\
1.10 \mathrm{E}+04 \\
1.38 \mathrm{E}+02 \\
\\
3.75 \mathrm{E}+03\end{array}$ \\
\hline
\end{tabular}




\section{Comparison of microsatellite and RADseq data}

Finally, we compared the results derived from population structure analyses on microsatellite and RADseq data to assess their suitability for addressing our phylogeographic question. It is important to note that differences between the full microsatellite and RADseq datasets could be attributable to one or a combination of the following; the number of populations, the geographic distribution of populations, the number of samples per population, the number of markers, or the information content of the marker type. To disentangle these sources of variation, we created two microsatellite data subsets; M2, which included only individuals used in RADseq, (excluding three individuals for which microsatellite data was incomplete, $n=146$, npops $=19$ ), and M3, which contained all individuals for which microsatellite data was available in populations that were used in RADseq $(n$ $=313$, npops $=19$; Table 3). This gave us three pairs of datasets for comparison: 1 ) RADseq Vs. M2: same individuals but different marker types, 2) M1 vs M2: full microsatellite dataset versus a subset of the populations, and 3) M2 vs M3: same populations but different number of individuals per population. This strategy enabled us to test for the influence of marker, sampling of populations and individuals per population respectively. Comparisons were performed between datasets on heterozygosities and pairwise $F_{\mathrm{st}} \mathrm{S}$ using both Pearson's product-moment correlation coefficient and paired Student's t-tests in R. IBD results were compared using Mantel tests (Jombart \& Ahmed 2011), and DAPC results were compared on the basis of similarity of number of inferred clusters and cluster sharing between populations.

\section{Results}

\section{Phylogenetic analyses of Mitochondrial data}

The combined 1090 bp alignment of 100 cytb C. carassius mtDNA sequences yielded 22 haplotypes, which were split across two well supported and highly differentiated phylogenetic lineages (Figure 2, Supplementary table 2). Lineage 1 was found in all northern European river catchments sampled, as well as eastern European (Dnieper) and southeastern European (Don and Volga) catchments, whereas Lineage 2 was almost exclusively confined to the River Danube catchment. There were a few exceptions to this clear geographical split however; two individuals, one from the Elbe and one from the Rhine in northern Germany, belonged to mtDNA Lineage 2, as did one individual from the River Lahn river catchment in western Germany. Also one population in the Czech Republic, located on the border between the Danube and Rhine river catchments, was found to contain individuals belonging to lineages 1 and 2 . 
The mean number of nucleotide differences within lineages 1 and 2 was 2.25 and 2.00, respectively, which equated to a sequence divergence $0.2 \%$ and $0.18 \%$, respectively. Between the two lineages there was an average of 22.5 nucleotide differences (2.06\% mean sequence divergence), with 19 of these being fixed. BEAST molecular clock analysis dated the split between lineages 1 and 2 to be 1.30-3.22 million years ago (MYA), with a median estimate of 2.26 MYA (Figure 2).

\section{Nuclear marker datasets and quality checking}

Microchecker showed no consistent signs of null alleles or allele dropout in microsatellite loci and no significant LD was found between any pairs of loci. No populations showed significant deviation from Hardy-Weinberg proportions (adjusted nominal level 0.0009).

After filtering raw RADseq data, de novo construction of loci across the 19 populations produced 35709 RADseq loci that were present in at least $70 \%$ of individuals in at least 17 populations. These loci contained a total of 29927 polymorphic SNPs (approx. 0.84 SNPs per locus). Only the first SNP in each RADseq locus was retained, to avoid confounding signals of LD. This yielded a total of 18908 loci with a mean coverage of 29.07 reads. Finally 5719 of these SNP loci were filtered out due to high $(>0.5)$ heterozygosity in at least one population. In doing so, we removed many high coverage tags (Supplementary Fig. 3), which was consistent with over-merged ohnologs having higher coverage (i.e. reads from more than two alleles) than correctly assembled loci. The final dataset therefore contained 13189 SNP loci, with a mean coverage of 27.72 reads.

\section{Within population diversity at nuclear loci}

Observed heterozygosity $\left(H_{\circ}\right)$, averaged across all microsatellite loci within a population, ranged from 0.06 (SWE9) to 0.44 (BLS), with a mean of 0.25 across all populations (SD = 0.105), and was highly correlated with $A_{\mathrm{r}}(t=19.67, P<0.001, \mathrm{df}=40)$, which ranged from 1.26 (FIN1) to 2.96 (POL3) with a mean of $1.92(\mathrm{SD}=0.51)$. Mean $H_{\circ}$ averaged across all RADseq loci for all populations was $0.013(\mathrm{SD}=0.013)$, ranged from 0.001 to 0.057 and was significantly correlated with $H_{\mathrm{o}}$ from microsatellite loci at populations shared between both datasets $(\mathrm{r}=0.69, t=3.74, P=$ $0.002, \mathrm{df}=15)$. Microsatellite $A_{\mathrm{r}}$ significantly decreased along an east to west longitudinal gradient $\left(\operatorname{adj} . R^{2}=0.289, P<0.001\right.$, Supplementary Figure $\left.4 \mathrm{~b}\right)$ consistent with decreasing diversity along colonisation routes. However, $A_{\mathrm{r}}$ did not decrease with increasing latitude (Adj $\mathrm{R}^{2}=-0.007, \mathrm{P}=$ 0.414, Supplementary Figure 4a). We also repeated this analysis after removing samples from mtDNA Lineage 2 in the Danube catchment. Again there was no relationship between $A_{\mathrm{r}}$ and latitude $\left(R^{2}=-0.023, P=0.254\right.$, Supplementary Figure $\left.4 \mathrm{c}\right)$, but the relationship between $A_{\mathrm{r}}$ and longitude was strengthened (adj. $R^{2}=0.316, P<0.001$, Supplementary Figure 4 d). 


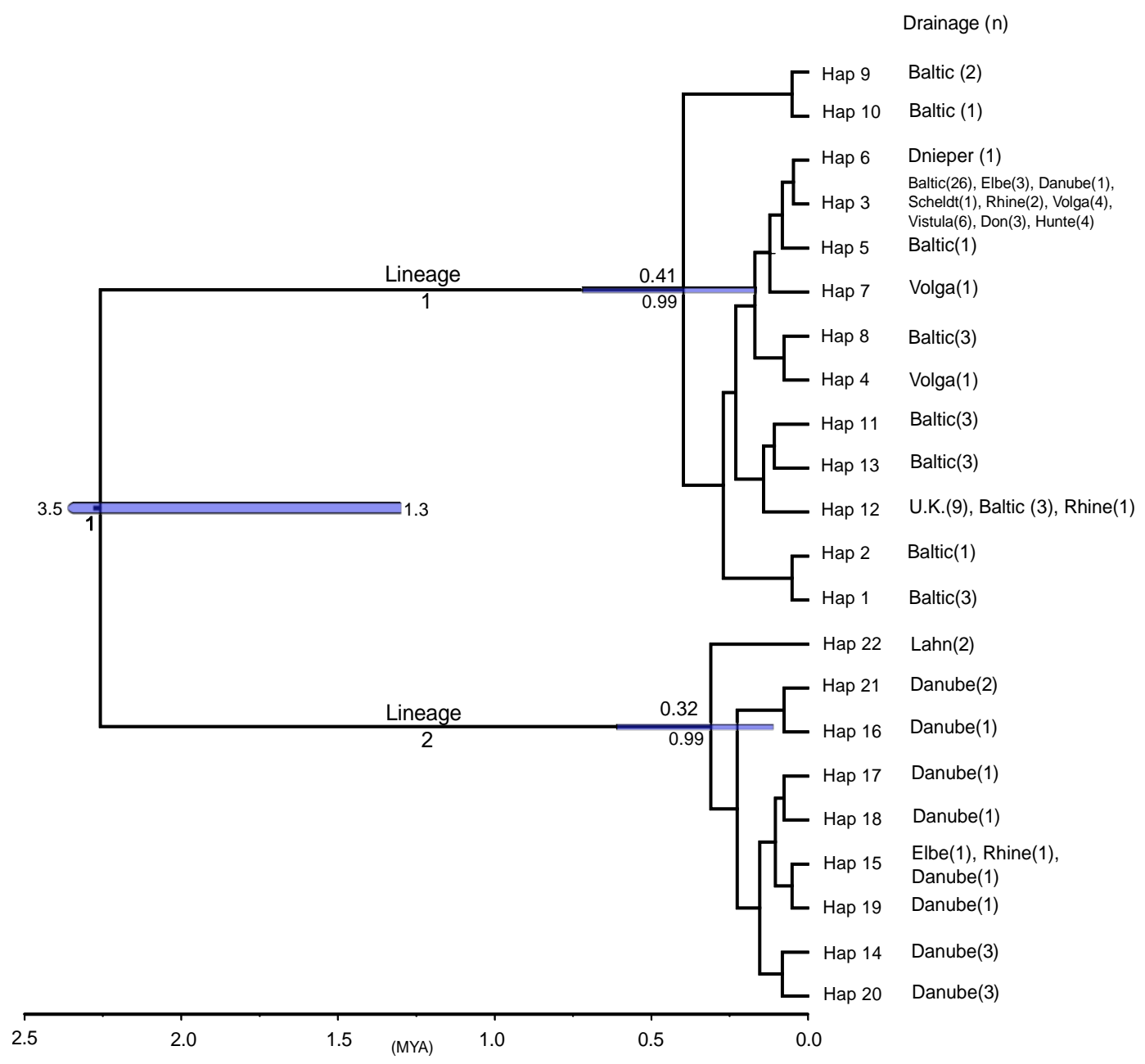

Figure 2. Maximum credibility tree calculated in BEAST for $100 \mathrm{C}$. carassius cytb sequences. For the three maximally supported nodes, age is given above and the posterior probability distribution is given below, with 95\% CI's represented by blue bars.

\section{Population Structure in Europe based on nuclear markers}

Population structure was strong, as predicted. Using the full (M1) microsatellite dataset, mean pairwise $F_{\text {sт }}$ was $0.413(\min =0.0$; BEL2 and BEL3), $\max =0.864$ (NOR2 vs GBR2), with 861 of the 1128 pairwise population comparisons being significant $F_{\text {ST }}(P<0.05$, Supplementary table 3). Pairwise $F_{\text {sт }}$ calculated from the RADseq dataset also showed strong structure ( 
Supplementary table 4), ranging from 0.067 (DEN1, DEN2) to 0.699 (NOR2, GBR4), and these values were highly correlated with the same population comparisons in the M3 microsatellite dataset $(\mathrm{r}=0.66, t=9.01, P<0.01, \mathrm{df}=104)$.

BIC scores obtained from initial DAPC analyses, using all 49 populations, indicated that between 11 and 19 genetic clusters (Supplementary Figure 5a) would be an appropriate model of the variation in the data. As a conservative estimate of population structure, we chose 11 clusters for use in the discriminant analysis, retaining eight principal components as recommended by the spline interpolation a-scores (Supplementary Figure 5a). This initial analysis showed that populations belonging to Cluster 10 (RUS1, Don river catchment) and Cluster 11 (GER3, GER4, CZE1, Danubian catchment) were highly distinct from clusters found in northern Europe (Figure 1b). Since the marked genetic differentiation between these three main clusters masked the more subtle population structure among northern European populations (see Figure 1b), we repeated the DAPC analysis without the populations from the Danube and Don (RUS1, GER3, GER4, CZE1, Figure 1b). The results of this second DAPC analysis revealed an IBD pattern of population structure, across Europe (Figure 1). Mantel tests excluding the Danubian and Don populations corroborated these results; showing significant correlation with geographic distance in northern Europe (adjusted $R^{2}=0.287, P<0.001$, Supplementary Figure 6a), with Danubian populations shown to be more diverged than their geography would predict (data not shown).

In the RADseq DAPC analysis, BIC scores suggested between four and ten genetic clusters, similar to the range inferred in the microsatellite data, and we therefore chose four clusters to take forward in the analysis (Supplementary Figure 5b). Following spline interpolation, we retained six principal components and kept two of the linear discriminants from the subsequent discriminant analysis (Supplementary Figure 5b). The inferred population structure showed that the Danubian population (HUN2) and the Don population (RUS1) were highly diverged from the northern European clusters. Unfortunately, HUN2 is not present in the microsatellite dataset for direct comparison, however both datasets, and the mtDNA data show the same pattern of high divergence between northern Europe and Danubian populations. DAPC analyses of RADseq data again showed an IBD pattern in northern European populations, which was confirmed with Mantel tests when the Danubian population HUN2 was excluded (adjusted $R^{2}=0.722, P<0.001$; Supplementary Figure 6b). 


\section{Postglacial recolonisation of $C$. carassius in Europe}

DAPC results of the 1000 SNP RADseq dataset used in DIYABC showed that it produced the same population structure as the full RADseq dataset (Supplementary Figure 7). For the broad-scale scenario tests in stage one of the DIYABC analysis, both logistic regression and direct approach identified Scenario 9 as being most likely to describe the true broad-scale demographic history (Supplementary Figure 8). Model checking showed that the observed summary statistics for our data fell well within those of the posterior parameter distributions for scenario 9 (Supplementary Figure 8c). Scenario 9 agrees with the mtDNA results, suggesting that the Danubian populations have made no major contribution to the colonisation of northern Europe. The median posterior distribution estimate of the divergence time between Danubian and northern European populations is 2.18 MYA (assuming a two-year generation time;(Tarkan et al. 2010), which is strikingly similar to that of mtDNA dating analysis. Scenario 9 also suggests that the northern European populations experienced a population size decline after the split of Pool 1 from the population in the Don river catchment, which lasted approximately 8920 years and reduced $N_{e}$ by $32 \%$.

In stage two of the DIYABC analysis, we tested the major variant scenarios for the colonisation of northern Europe. In assessing the relative probabilities of scenarios, there was some discrepancy between the direct approach, which revealed Scenario 14 to be most likely, and the logistic regression, which favoured Scenario 13 (with Scenario 14 being the second most likely). However, the goodness-of-fit model checking showed that the observed dataset fell well within the posterior parameter distributions for Scenario 14 (Supplementary Figure 9a), but not for Scenario 13 (not shown). Therefore, Scenario 14 was carried forward into stage three in which we tested six more scenarios (Supplementary Figure 2b) to compare combinations of bottlenecks using the same population tree topology as in Scenario 14. Direct approach, logistic regression and model checking all found scenario 14d to be the most likely (Supplementary Figure 9b), we therefore accepted this as the scenario for the colonisation of $C$. carassius in northern Europe (Supplementary Figure 9b). This scenario infers an initial split between two sub-lineages in northern Europe approximately 33600 YBP (Figure 4), one of which re-colonised northwest Europe and one that re-colonised Finland through the Ukraine and Belarus. Scenario $14 \mathrm{~d}$ also inferred a secondary contact between these sublineages approximately 15940 YBP, resulting in the populations currently present in Poland; these admixed populations provided the source of one colonisation across the Baltic into Sweden, and a second route was inferred into southern Sweden from Denmark (Table 3, Supplementary Figure $9 b)$. 


\section{Comparing microsatellite datasets and RAD-sequencing data}

The results from the RADseq $(n=149$, npops $=16$ ) dataset and the full microsatellite dataset (M1, $n=848$, npops $=49$ ) largely agreed on the inferred structure and cluster identity of populations. However, there were some important differences between them. Firstly, the IBD pattern of population structure in northern Europe was much stronger in the RADseq data $\left(\mathrm{R}^{2}=0.722, P<\right.$ 0.001) (Supplementary Figure 6$)$ compared to the M1 dataset $\left(\mathrm{R}^{2}=0.287, P<0.001\right)$ (excluding Danubian populations and SWE9 from both datasets, Supplementary Figure 6). Secondly, clusters inferred by the RADseq DAPC analysis are much more distinct, i.e. there is much lower withincluster, and higher between-cluster variation in the RADseq results than in the M1 dataset results (Figure 3).

Table 3. Summary statistics for M1, M2, M3 and RADseq datasets. RAD contains all RAD-seq data, M1 contains all microsatellite data, M2 contains only microsatellite for the individuals used in the RAD-seq, and M3 contains all microsatellite data for all individuals that were available in populations that were used in RAD-seq.

\begin{tabular}{|c|c|c|c|c|c|c|}
\hline Dataset & Description & $\begin{array}{l}\mathrm{N} \\
\text { samples }\end{array}$ & $\begin{array}{l}\text { Mean N } \\
\text { samples/ } \\
\text { pop }\end{array}$ & N. loci & $\begin{array}{l}\text { Mean } \\
\text { N.alleles/ } \\
\text { pop }\end{array}$ & $\begin{array}{l}\text { Mean } \\
\text { N.alleles/locus }\end{array}$ \\
\hline RAD & RADseq data only & 149 & $8.95 \pm 1.4$ & 13189 & 6723 & 2 \\
\hline M1 & Full Microsatellite dataset & 848 & $17.2 \pm 9.5$ & 13 & $27 \pm 8.8$ & 7.6 \\
\hline $\mathrm{M} 2$ & $\begin{array}{l}\text { Microsatellites for RADseq } \\
\text { samples only }\end{array}$ & 146 & $9.125 \pm 0.8$ & 13 & $24.4 \pm 7.3$ & $7.8 .4 \pm 5.1$ \\
\hline M3 & $\begin{array}{l}\text { Microsatellites for all } \\
\text { samples in populations } \\
\text { used in RADseq }\end{array}$ & 313 & $19.6 \pm 9.0$ & 13 & $27.4 \pm 8.1$ & $11.23 \pm 7.6$ \\
\hline
\end{tabular}

As the properties of the RADseq and M1 datasets differ in four respects, namely marker type, number of populations, number of samples per population (Table 3) and uniformity of sampling locations, (Supplementary Figure 10), it was not possible to identify the cause of discrepancies in their results. Therefore, below we report the results from the pair-wise dataset comparisons, which isolate the effects of these parameter differences.

1) MI Vs. M3: the effect that the number of populations and the uniformity of sampling locations might have on inferred population structure. The geographic distribution of sampling locations was more clustered in M1 (full microsatellite dataset) than in M3 (containing microsatellite for samples in populations used in RADseq, Supplementary Figure 10), and IBD patterns were considerably stronger in the M3 subset (adj. $R^{2}=0.447, P<0.001$ ) than in the full M1 dataset (adj. $R^{2}=0.287, P<$ 
0.001). In contrast DAPC results were very similar between datasets, with cluster number, structure and population identity of clusters generally agreeing well (Figure 1, Figure 3c).

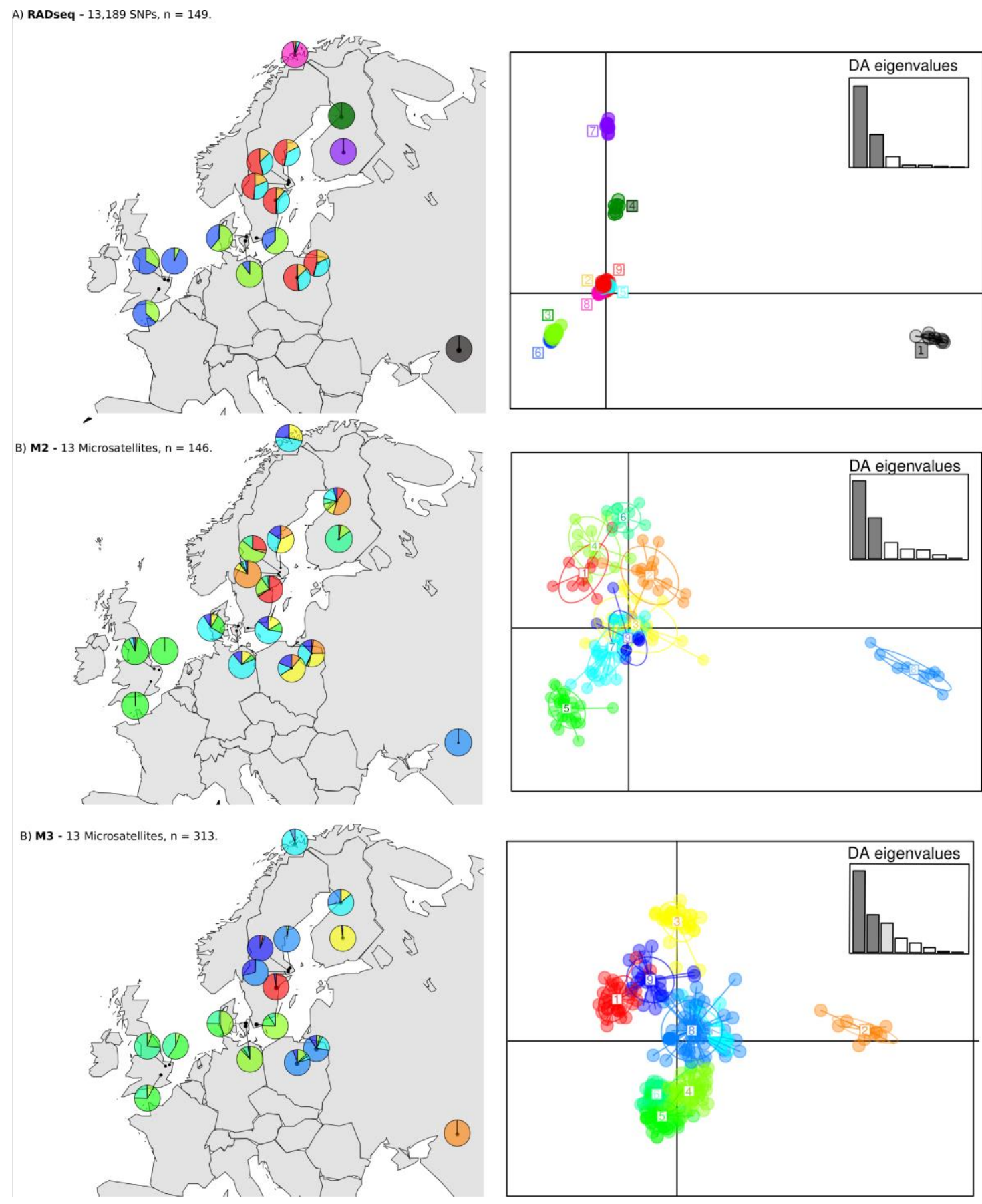

Figure 3. Comparison of DAPC results using RADseq dataset a), M2 dataset b) and M2 dataset c). Colours correspond between DAPC scatter plots and maps within but not between panels.

2) M2 Vs. M3: the effect of reducing the number of samples per population on the inferred population structure. The number of samples per population in the M2 subset (microsatellite data only for the samples used in RADseq, mean $=9.125 \pm 0.8$ ) was significantly lower than that of the M3 subset (mean, 19.6 $\pm 9.0, t=-4.66, \mathrm{df}=15, P<0.001$ ), as was the number of alleles per population $(\mathrm{M} 2$ mean $=24.4 \pm 7.3, \mathrm{M} 3$ mean $=27.4 \pm 8.1, t=-5.72, \mathrm{df}=15, P<0.001)$. Population 
heterozygosities were significantly different between M2 (mean $=0.21)$ and M3 (mean $=0.23), t=-$ 2.4 , df $=15, P=0.012)$, but highly correlated $(\mathrm{r}=0.94, t=-11.13, P<0.001, \mathrm{df}=15)$. Pairwise $F_{\mathrm{ST}}$ sere very strongly correlated $(\mathrm{r}=0.97, t=46.26, P<0.001, \mathrm{df}=105)$, but again, still significantly different between the two datasets (M2 mean $=0.46$, M3 mean $=0.49, t=-6.21, P<$ $0.001, \mathrm{df}=15$, Table 4). The patterns of IBD were almost identical for $\mathrm{M} 2\left(\mathrm{R}^{2}=0.455, P<0.001\right)$ and M3 $\left(\mathrm{R}^{2}=0.447, P<0.001\right.$, Supplementary Figure 6$)$ and population structure inferred by DAPC was again similar. BIC scores suggested a similar range of cluster number for M2 and M3, the smallest of which was nine in both cases.

Table 4. Pearson's product-moment correlation coefficients and Pared t-tests comparing Heterozygosities and FSTs between M2, M3 and RADseq datasets. *** $P=<0.001, * * P=<0.005, * P=<0.05$.

\begin{tabular}{c|lll} 
Heterozygosities $(\mathbf{d f}=\mathbf{1 8})$ & \multicolumn{3}{l}{ Pearsons correlation coefficient $(\mathbf{t})$} \\
\hline \multirow{3}{*}{ Paired T-tests } & M2 & $11.13^{* * *}$ & $3.85^{* *}$ \\
& $-2.4^{*}$ & M3 & $3.86^{* *}$ \\
& $-9.71^{* * *}$ & $-9.29^{* * *}$ & RAD \\
FST (df = 105) & \multicolumn{3}{l}{} \\
\hline & Pearsons & correlation coefficient $(\mathbf{t})$ \\
\hline & M2 & $46.26^{* * *}$ & $10.09^{* * *}$ \\
& $-6.21^{* * *}$ & M3 & $9.05^{* * *}$ \\
& $13.74^{* * *}$ & $15.12^{* * *}$ & RAD
\end{tabular}

3) RADseq Vs. M3: The effect of the number and the type of markers used on the phylogeographic results. We compared the results from the RADseq and M2 datasets, which contain exactly the same samples (with the exception of three individuals missing in M2). Significant correlations were again found between heterozygosities estimated for the two datasets $(\mathrm{r}=0.69, t=3.73, P=0.002$, $\mathrm{df}=15)$ and pair-wise $F_{\mathrm{ST}}(\mathrm{r}=0.70, t=10.09, P<0.001, \mathrm{df}=105)$, but RADseq data yielded much lower pairwise $F_{\mathrm{ST}} \mathrm{S}($ mean $\mathrm{RAD}=0.29$, mean M2 $=0.46, t=13.74, P<0.001$, df $=15$ ). DAPC analysis of RADseq data resolved populations into much more distinct clusters (Figs. 3a, 3b), and the IBD pattern found was considerably stronger in the RADseq $\left(\mathrm{R}^{2}=0.722, P<0.001\right)$ dataset compared to M2 $\left(\mathrm{R}^{2}=0.455, P<0.001\right.$, Supplementary Figure 6$)$.

\section{Discussion}

In this study, we aimed to simultaneously produce a phylogeographic framework on which to base conservation strategies for $C$. carassius in Europe, and compare the relative suitability of genomewide SNP markers and microsatellite markers for such an undertaking. Through comparison of the inferred population structure from microsatellite and genome-wide SNP data, we show that there 
are important differences in the results from each data type, attributable predominantly to marker type, rather than within population sampling or spatial distribution of samples. However, despite these differences, all three data types used (mitochondrial, microsatellite and SNP data) agree that, unlike many other European freshwater fish for which phylogeographic data is available, $C$. carassius has not been able to cross the Danubian catchment boundary into northern Europe. This has resulted in two, previously unknown, major lineages of $C$. carassius in Europe, which we argue should be considered as separate conservation units.

\section{Phylogeography and postglacial recolonisation of C. carassius in Europe}

The most consistent result across all three marker types (mtDNA sequences, microsatellites and RADseq) was the identification of two highly-divergent lineages of $C$. carassius in Europe. The distinct geographic distribution of these lineages; Lineage 1 being widely distributed across north and eastern Europe and Lineage 2 generally only in the River Danube catchment, indicates a longstanding barrier to gene flow between these geographic regions. Bayesian inference based on mtDNA phylogeny and $\mathrm{ABC}$ analysis of RADseq data showed remarkable agreement, estimating that these lineages have been isolated for 2.3 MYA (95\% CI $=1.30-3.22)$ and $2.2(95 \% \mathrm{CI}=2-$ 6.12) MYA respectively, which firmly places the event at the beginning of the Pleistocene (2.6 MYA;(Gibbard \& Head 2009). This pattern differs substantially from the general phylogeographic patterns observed in other European freshwater fish. Indeed, previous studies have shown that the Danube catchment has been an important source for the postglacial recolonisation of freshwater fish into northern Europe or during earlier interglacials in the last 0.5 MYA. For example, chub Leuciscus cephalus (Durand et al. 1999), Eurasian perch Perca fluviatilis (Nesbø et al. 1999), riffle minnow Leuciscus souffia (Salzburger et al. 2003), grayling Thymallus thymallus(Gum et al. 2009), European barbel Barbus barbus (Kotlík \& Berrebi 2001), and roach Rutilus rutilus (Larmuseau et al. 2009) all crossed the Danube catchment boundary into northern drainages such as those of the rivers Rhine, Rhône and Elbe during the mid-to-late Pleistocene. The above species occur in lotic habitats, and most are capable of relatively high dispersal. In contrast $C$. carassius has a very low propensity for dispersal, and a strict preference for the lentic backwaters, isolated ponds and small lakes(Holopainen et al. 1997; Culling et al. 2006); Copp 1991). We therefore hypothesise that these ecological characteristics of $C$. carassius have reduced its ability to traverse the upper Danubian watershed, which lies in a region characterised by the Carpathian Mountains and the Central European Highlands. This region may have acted as a barrier to the colonisation of $C$. carassius into northern European drainages during the Pleistocene. It should be noted, however, that phylogeography of two species, the spined loach Cobitis taenia and European weatherfish Misgurnus fossilus, does not support this hypothesis as a general pattern for floodplain species 
(Janko et al. 2005; Culling et al. 2006). The former is the only species that we know of other than C. carassius showing long-term isolation between the Danube and northern European catchments, but has lotic habitat preferences and good dispersal abilities (Janko et al. 2005; Culling et al. 2006), whereas the latter inhabits similar ecosystems as C. carassius, with low dispersal potential, but has colonised northern Europe from the Danube catchment(Bohlen et al. 2006, 2007).

There is one notable exception to the strict separation between Danubian and northern European $C$. carassius populations. The population CZE1, located in the River Lužnice catchment (Czech Republic), which drains into the River Elbe, clusters with Danubian populations in both the microsatellite and mtDNA data. The sample site from the River Lužnice is located in very close proximity to the Danubian catchment boundary and is situated in a relatively low lying area. Therefore some recent natural movements across the watershed between these river catchments, either through river capture events or ephemeral connections, could have been possible. A similar pattern has been shown in some European bullhead Cottus gobio populations along the catchment Danube/Rhine catchment border (Riffel \& Schreiber 1995). We also observed the presence of two mtDNA haplotypes from Lineage 2 in some individuals from northern German populations (GER1, GER2, GER8), however, one of these haplotypes was shared with Danubian individuals and the results were not confirmed by nuclear markers. Overall this is most likely to be the result of occasional human mediated long-distance dispersal for the purposes of intentional stocking.

Population structure within Lineage 1 is characterised by a pattern of IBD and a loss of allelic richness from eastern to western Europe. This is consistent with the most likely colonisation scenario identified by the DIYABC analysis, indicating a general southeast to northwest expansion from the Ponto-Caspian region towards central and northern Europe (Figure 4). The Ponto-Caspian region, and in particular the Black Sea basin, was an important refugium for freshwater fishes during the Pleistocene glacials, and a similar colonisation route has been inferred for many other freshwater species in northern Europe(Nesbø et al. 1999; Durand et al. 1999; Culling et al. 2006; Costedoat \& Gilles 2009). The DIYABC analysis also suggests that there was an interval of $>200$ 000 years between the split of the Don population $(\approx 270000$ years ago $)$ and the next split in the scenario (approx. 33600 years ago), which marks the main expansion across central and northern Europe. It appears that no further population divergence can be dated back to the time interval between the Riss/Saalian and the Würm/Weichelian glacial periods. This may be because the range of $C$. carassius has not undergone a major change during that time interval, but it is more likely that the signal of expansion during the Riss-Würm interglacial has been eradicated through a subsequent range contraction during the Würm/Weichelian glacial period. The model also suggests that the 
Würm/Weichelian period was accompanied by a sustained but moderate reduction in population size over almost 9000 years (Bottleneck A, Figure 4), which may reflect general population size reductions during the Riss glaciations or a series of shorter bottlenecks during subsequent range expansion (Ramachandran et al. 2005, Simon et al 2015, Hewitt 2000).

DIYABC analyses inferred the colonisation of northern Europe by two sub-lineages within the mtDNA Lineage 1, which were isolated from each other approximately 33600 years ago. These sub-lineages may reflect two glacial refugia resulting from the expansion of the Weichselian ice cap to its maximum extent roughly 22000 years ago (see hypothetical refugia II and III in Figure 4). The western sub-lineage underwent a second long period of population decline (Bottleneck B, Figure 4), which may again represent successive founder effects during range expansion. There is then evidence of secondary contact between these sub-lineages (node b, approximately $\approx 15940$ years ago), contributing to the genetic variation now found in Poland. This inferred admixture event may represent one of the numerous inundation and drainage capture events, which resulted from the melting of the Weichselian ice cap, that are known to have occurred around this time (Grosswald 1980; Gibbard et al. 1988; Arkhipov et al. 1995). However, as the colonisation of Europe was likely to have occurred via the expansion of colonisation fronts (i.e. dashed contour lines in Figure 4), rather than along linear paths, it could also be indicative of the known IBD gradient between the inferred western and eastern sub-lineages. Such a gradient (eg. between northwestern and northeastern Europe) may give false signals of admixture between intermediate populations, such as those in Poland.

The colonisation of the Baltic sea basin also seems to have been complex, with three independent routes inferred by DIYABC scenario 14d; one recent route through Denmark into southern Sweden, one to the east of the Baltic Sea, through Finland, and one across the Baltic Sea, from populations related to those in Poland (Pool 4). The first of these agrees well with the findings of Janson et al.(2014), whereby populations, including SWE8 from our study (SK3P in Janson et al.(2014), in this region were found to be distinct from those in central Sweden. The eastern route shows similarities to the colonisation patterns of $P$. fluvilatilis, which is hypothesised to have had a refugium east of Finland(Nesbø et al. 1999) during the most recent glacial period. This is certainly also plausible in C. carassius and may account for the distinctiveness of Finnish populations seen in microsatellites and RADseq DAPC analysis. The last colonisation route, across the Baltic Sea from mainland Europe, may have coincided with the freshwater Lake Ancylus stage of the Baltic Sea's evolution, which existed from $\approx 10600$ to 7500 years ago (Björck 1995; Kostecki 2014). The Lake Ancylus stage likely provided a window for the colonisation of many of the species now resident in 
the Baltic, and has been proposed as a possible window for the colonisation of Thymallus thymallus(Koskinen et al. 2000), Cobitis taenia,(Culling et al. 2006), Cottus gobio(Kontula \& Väinölä 2001) and four Coregonus species(Svärdson 1998). Consistent with this, we found strong similarity between populations from Fasta Åland, southern Finland and central Sweden, suggesting that shallow regions in the central part of Lake Ancylus (what is now the Åland Archipelago), may have provided one route across Lake Ancylus.

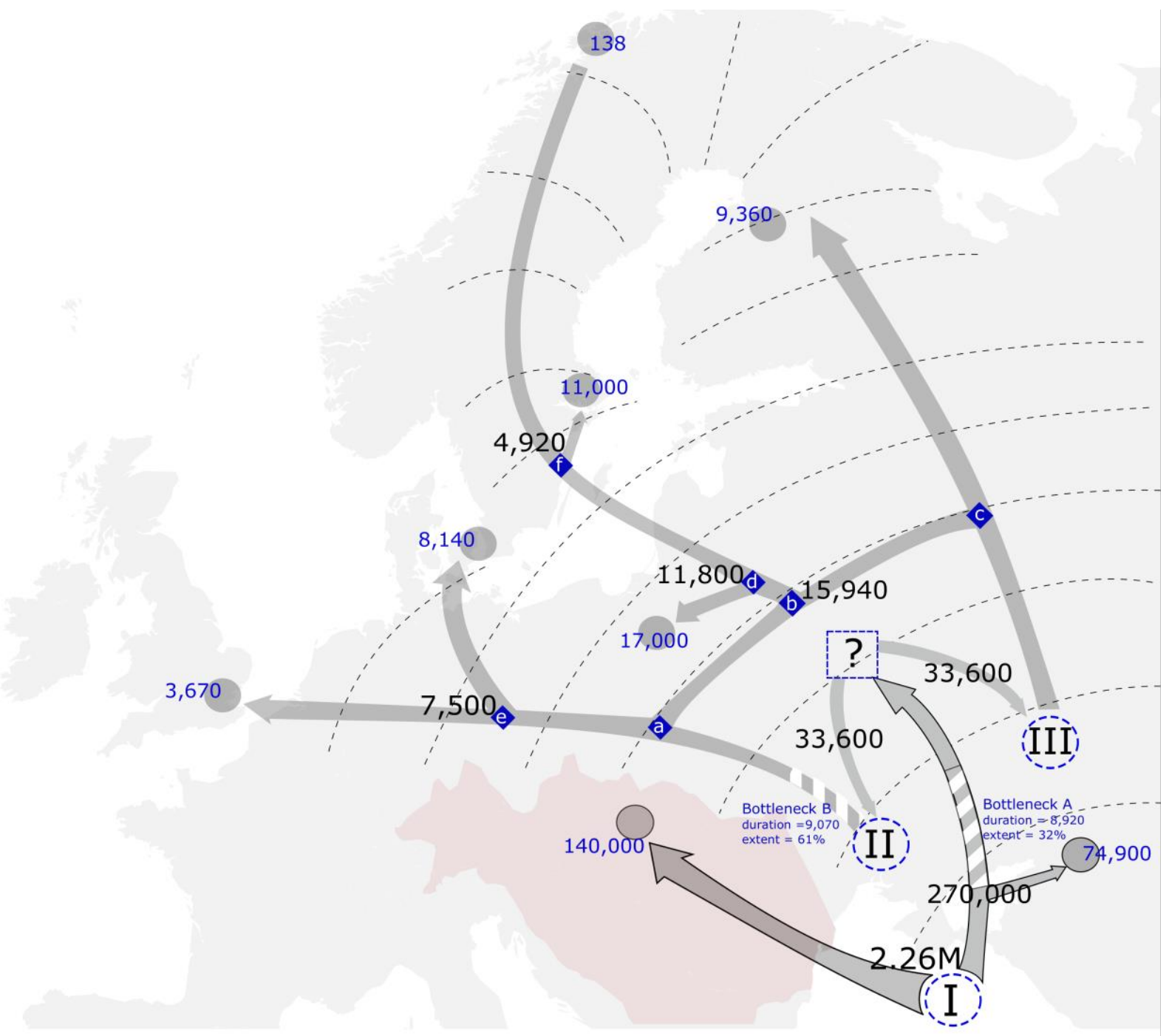

Figure 4. The postglacial recolonisation of C. carassius in Europe. Arrows represent the relationships between population pools used in DIYABC (grey circles) as inferred from Stage 1, scenario 9 (arrows outlined in black) and Stage 3, scenario 14d (arrows with no outline) analyses on RADseq data. Bottlenecks are represented by white-striped sections of arrows. Posterior time estimates in years for each demographic event are given in black, and estimates of $\mathrm{Ne}$ are given in blue. Blue diamonds represent ancestral populations inferred by DIYABC and the labels (a-f) correspond to their mention in the text. Hypothetical expansion fronts are represented by dashed contour lines and the Danube river catchment is shaded red. Hypothetical glacial refugia are represented by dashed blue circles (I - III). The blue dashed box (?) 
represents our inference that C. carassius expanded into central and perhaps northern Europe during the RissWürm interglacial, however we cannot estimate this range.

It is also likely that the contemporary distribution of $C$. carassius in the Baltic has been influenced by human translocations. C. carassius were often used as a food source in monasteries in many parts of Sweden(Janson et al. 2014), and the Baltic island of Gotland(Rasmussen 1959; Svanberg et al. 2013) was an important trading port of the Hanseatic League - a commercial confederation that dominated trade in northern Europe from the $13^{\text {th }}$ to $17^{\text {th }}$ centuries. Previous data suggest that $C$. carassius was transported from the Scania Province, southern Sweden, where C. carassius aquaculture was common at least during the $17^{\text {th }}$ century, to parts further north (Svanberg et al. 2013; Janson et al. 2014).

\section{Implications for the conservation of $\mathrm{C}$. carassius in Europe}

The two C. carassius lineages exhibit highly-restricted gene flow between them and are the highest known organisational level within the species. They therefore meet the genetic criteria for Evolutionarily Significant Units (ESUs) as described in (Fraser \& Bernatchez 2001). This is especially important in light of the current $C$. carassius decline in the Danubian catchment (Bănărescu 1990; Navodaru et al. 2002; Lusk et al. 2010; Savini et al. 2010). The conservation of C. carassius in central Europe must therefore take these catchment boundaries into consideration, as opposed to political boundaries. A first step would be to include C. carassius in Red Lists, not only for individual countries, but at the regional (e.g. European Red List of Freshwater Fishes; (Freyhof \& Brooks 2011) and global (IUCN 2014) scales, and we hope that the evidence presented here will facilitate this process. Within the northern European lineage, the Baltic Sea basin shows high levels of population diversity, likely owing to its complex colonisation history. As such, the Baltic represents an important part of the $C$. carassius native range. Although $C$. carassius is not currently thought to be threatened in the Baltic region, $C$. gibelio is invading this region and is considered a threat (Urho \& Lehtonen; Deinhardt 2013).

\section{Microsatellites vs RADseq for phylogeography}

Broad conclusions drawn from each of our RADseq-derived SNPs, full or partial microsatellite datasets are consistent, demonstrating deep divergence between northern and southern European populations and an IBD pattern of population structure in northern Europe. However, two striking differences exist in the phylogeographic results produced by RADseq compared to those of the microsatellite datasets. Firstly, the IBD pattern inferred from RADseq data was considerably 
stronger than for any of the microsatellite datasets. This effect was also found by Coates et al. (2009) when comparing SNPs and microsatellites, who postulated that it was driven by the differences in mutational processes of the markers. The second major difference between RADseq and microsatellite results was that clusters inferred by DAPC from the RADseq data were considerably more distinct compared to the full microsatellite dataset, emphasising the fine scale structure in the data (which is particularly apparent in the northern Finnish populations). We ruled out the possibility of these differences being caused by the reduction in number of populations, their spatial uniformity or number of individuals per population used in RADseq by creating two partial microsatellite datasets and comparing these to results from the RADseq-SNPs. Differences between marker types were consistently reproducible whether full or partial microsatellite datasets were used in the analyses.

It is also worth noting that the number of populations or the number of samples per population had no apparent impact on IBD and DAPC results between the microsatellite datasets. This is in contrast to predictions of patchy sampling of IBD made by Schwartz and McKelvey (2009), perhaps because of the strong population structure in C. carassius, and likelihood that a sufficiently informative number of populations was included even in the reduced datasets.

\section{Conclusions}

We have identified the most likely routes of post-glacial colonisation in C. carassius, which deviate from the general patterns observed in other European freshwater fishes. This has resulted in two, previously-unidentified major lineages in Europe, which future broad-scale monitoring and conservation strategies should take into account.

Although our RADseq sampling design included only $17.6 \%$ of samples included in the full microsatellite dataset this was sufficient to produce a robust phylogeography in agreement with the microsatellite dataset, and emphasised the fine scale structure among populations. We therefore conclude that RADseq would present the better option for the phylogeography of $C$. carassius, with the huge number of SNP loci overcoming the limitations imposed by reduced sample number. 


\section{References}

Andrews S (2010) FastQC: a quality control tool for high throughput sequence data. Babraham Bioinformatics.

Arkhipov SA, Ehlers J, Johnson RG, Wright HE Jr (1995) Glacial drainage towards the Mediterranean during the Middle and Late Pleistocene. Boreas, 24, 196-206.

Balkenhol N, Landguth EL (2011) Simulation modelling in landscape genetics: on the need to go further. Molecular ecology, 20, 667-670.

BEAST Tutorial - Tree priors and dating

Bernatchez L, Wilson CC (1998) Comparative phylogeography of Nearctic and Palearctic fishes. Molecular ecology, 7, 431-452.

Bianco P (1990) Potential role of the palaeohistory of the Mediterranean and Paratethys basins on the early dispersal of Euro-Mediterranean freshwater fishes. Ichthyological exploration of freshwaters, 1.

Björck S (1995) A review of the history of the Baltic Sea, 13.0-8.0 ka BP. Quaternary international: the journal of the International Union for Quaternary Research, 27, 19-40.

Bohlen J, Šlechtová V, Bogutskaya N, Freyhof J (2006) Across Siberia and over Europe: Phylogenetic relationships of the freshwater fish genus Rhodeus in Europe and the phylogenetic position of R. sericeus from the River Amur. Molecular phylogenetics and evolution, 40, 856-865.

Bohlen J, ŠLechtová V, Doadrio I, Ráb P (2007) Low mitochondrial divergence indicates a rapid expansion across Europe in the weather loach, Misgurnus fossilis (L.). Journal of fish biology, 71, $186-194$.

Bănărescu P (1990) Zoogeography of Fresh Waters. Vol. 1. General Distribution and Dispersal of Freshwater Animals. Aula-Verlag, Wiesbaden.

Bănărescu P (1992) Zoogeography of fresh waters. Vol. 2. Distribution and dispersal of freshwater animals in North America and Eurasia. Aula-Verlag, Wiesbaden.

Catchen J, Hohenlohe PA, Bassham S, Amores A, Cresko WA (2013) Stacks: an analysis tool set for population genomics. Molecular ecology, 22, 3124-3140.

Coates BS, Sumerford DV, Miller NJ et al. (2009) Comparative performance of single nucleotide polymorphism and microsatellite markers for population genetic analysis. The Journal of heredity, 100, 556-564.

Copp GH (1991) Typology of aquatic habitats in the great ouse, a small regulated lowland river. Regulated Rivers: Research \& Management, 6, 125-134.

Copp G, Sayer C (2010) Norfolk Biodiversity Action Plan-Local Species Action Plan for Crucian Carp (Carassius carassius). Norfolk Biodiversity Partnership Reference: LS 3. Fisheries \& Aquaculture Science, Lowestoft. 
Copp G, Tarkan S, Godard M, Edmonds N, Wesley K (2010) Preliminary assessment of feral goldfish impacts on ponds, with particular reference to native crucian carp. Aquatic invasions, $\mathbf{5}$, 413-422.

Copp GH, Černý J, Kováč V (2008) Growth and morphology of an endangered native freshwater fish, crucian carp Carassius carassius, in an English ornamental pond. Aquatic conservation: marine and freshwater ecosystems, 18, 32-43.

Cornuet JM, Luikart G (1996) Description and Power Analysis of Two Tests for Detecting Recent Population Bottlenecks From Allele Frequency Data. Genetics, 144, 2001-2014.

Cornuet J-M, Pudlo P, Veyssier J et al. (2014) DIYABC v2.0: a software to make approximate Bayesian computation inferences about population history using single nucleotide polymorphism, DNA sequence and microsatellite data. Bioinformatics .

Costedoat C, Gilles A (2009) Quaternary pattern of freshwater fishes in Europe: comparative phylogeography and conservation perspective. Conservation ....

Culling MA, Janko K, Boron A et al. (2006) European colonization by the spined loach (Cobitis taenia) from Ponto-Caspian refugia based on mitochondrial DNA variation. Molecular ecology, 15, 173-190.

Davey JW, Cezard T, Fuentes-Utrilla P et al. (2012) Special features of RAD Sequencing data: implications for genotyping. Molecular ecology, 22, 3151-3164.

Deinhardt M (2013) The invasive potential of Prussian carp in Finland under the light of a novel semi-clonal reproductive mechanism. Bio- ja ympäristötieteiden laitos, Jyväskylän yliopisto.

Dowling TE, Tibbets CA, Minckley WL, Smith GR, McEachran JD (2002) Evolutionary Relationships of the Plagopterins (Teleostei: Cyprinidae) from Cytochrome b Sequences. Copeia, 2002, 665-678.

Drummond AJ, Suchard MA, Xie D, Rambaut A (2012) Bayesian phylogenetics with BEAUti and the BEAST 1.7. Molecular biology and evolution, 29, 1969-1973.

Durand JD, Persat H, Bouvet Y (1999) Phylogeography and postglacial dispersion of the chub (Leuciscus cephalus) in Europe. Molecular ecology, 8, 989-997.

Emerson KJ, Merz CR, Catchen JM et al. (2010) Resolving postglacial phylogeography using highthroughput sequencing. Proceedings of the National Academy of Sciences, 107, 16196-16200.

Epperson BK, Mcrae BH, Scribner K et al. (2010) Utility of computer simulations in landscape genetics. Molecular ecology, 19, 3549-3564.

Fraser DJ, Bernatchez L (2001) Adaptive evolutionary conservation: towards a unified concept for defining conservation units. Molecular ecology, 10, 2741-2752.

Freyhof J, Brooks E (2011) European red list of freshwater fishes.

Gibbard P, Head MJ (2009) The Definition of the Quaternary System/Era and the Pleistocene Series/Epoch. Quaternaire, 20, 125-133. 
Gibbard PL, Rose J, Bridgland DR (1988) The History of the Great Northwest European Rivers During the Past Three Million Years [and Discussion]. Philosophical transactions of the Royal Society of London. Series B, Biological sciences, 318, 559-602.

Goudet J (2001) FSTAT, a program to estimate and test gene diversities and fixation indices. Université de Lausanne.

Grosswald MG (1980) Late Weichselian ice sheet of Northern Eurasia. Quaternary Research, 13, $1-32$.

Gum B, Gross R, Geist J (2009) Conservation genetics and management implications for European grayling, Thymallus thymallus: synthesis of phylogeography and population genetics. Fisheries management and ecology, 16, 37-51.

Hasegawa M, Kishino H, Yano T (1985) Dating of the human-ape splitting by a molecular clock of mitochondrial DNA. Journal of molecular evolution, 22, 160-174.

Hauser L, Baird M, Hilborn R, Seeb LW, Seeb JE (2011) An empirical comparison of SNPs and microsatellites for parentage and kinship assignment in a wild sockeye salmon (Oncorhynchus nerka) population. Molecular ecology resources, 11 Suppl 1, 150-161.

Hazewinkel M (Ed.) (1994) Encyclopeidia of Mathematics (set). Kluwer, Dordrecht, Netherlands.

Henkel CV, Dirks RP, Jansen HJ et al. (2012) Comparison of the exomes of common carp (Cyprinus carpio) and zebrafish (Danio rerio). Zebrafish, 9, 59-67.

Hess JE, Matala AP, Narum SR (2011) Comparison of SNPs and microsatellites for fine-scale application of genetic stock identification of Chinook salmon in the Columbia River Basin. Molecular ecology resources, 11, 137-149.

Hewitt GM (1999) Post-glacial re-colonization of European biota. Biological journal of the Linnean Society. Linnean Society of London, 68, 87-112.

Hoban SM, Gaggiotti OE, Bertorelle G (2013) The number of markers and samples needed for detecting bottlenecks under realistic scenarios, with and without recovery: a simulation-based study. Molecular ecology, 22, 3444-3450.

Holopainen IJ, Aho J, Vornanen M, Huuskonen H (1997) Phenotypic plasticity and predator effects on morphology and physiology of crucian carp in nature and in the. Journal of fish biology, 50, 781-798.

Holopainen IJ, Oikari A (1992) Ecophysiological effects of temporary acidification. Annales Zoologici Fennici, 29, 29-38.

Holopainen IJ, Tonn WM, Paszkowski CA Tales of two fish: the dichotomous biology of crucian carp (Carassius carassius (L.)) in northern Europe.

Hänfling B, Bolton P, Harley M, Carvalho GR (2005) A molecular approach to detect hybridisation between crucian carp (Carassius carassius) and non-indigenous carp species (Carassius spp. and Cyprinus carpio). Freshwater biology, 50, 403-417. 


\section{IUCN (2014) The IUCN Red List of Threatened Species.}

Janko K, Culling MA, Ráb P, Kotlík P (2005) Ice age cloning--comparison of the Quaternary evolutionary histories of sexual and clonal forms of spiny loaches (Cobitis; Teleostei) using the analysis of mitochondrial DNA variation. Molecular ecology, 14, 2991-3004.

Janson S, Wouters J, Bonow M, Svanberg I, Olsén KH (2014) Population genetic structure of crucian carp (Carassius carassius) in man-made ponds and wild populations in Sweden. Aquaculture international: journal of the European Aquaculture Society, 1-10.

Jombart T, Ahmed I (2011) adegenet 1.3-1: new tools for the analysis of genome-wide SNP data. Bioinformatics , 27, 3070-3071.

Jombart T, Devillard S, Balloux F (2010) Discriminant analysis of principal components: a new method for the analysis of genetically structured populations. BMC genetics, 11, 94.

Kontula T, Väinölä R (2001) Postglacial colonization of Northern Europe by distinct phylogeographic lineages of the bullhead, Cottus gobio. Molecular ecology, 10, 1983-2002.

Koskinen MT, Ranta E, Piironen J et al. (2000) Genetic lineages and postglacial colonization of grayling (Thymallus thymallus, Salmonidae) in Europe, as revealed by mitochondrial DNA analyses. Molecular ecology, 9, 1609-1624.

Kostecki R (2014) Stages of the Baltic Sea evolution in the geochemical record and radiocarbon dating of sediment cores from the Arkona Basin. Oceanological and Hydrobiological Studies, 43, $237-246$.

Kotlík P, Berrebi P (2001) Phylogeography of the barbel (Barbus barbus) assessed by mitochondrial DNA variation. Molecular ecology, 10, 2177-2185.

Landguth EL, Fedy BC, OYLER-McCANCE SJ et al. (2012) Effects of sample size, number of markers, and allelic richness on the detection of spatial genetic pattern. Molecular ecology resources, 12, 276-284.

Larmuseau MHD, Freyhof J, Volckaert FAM, Van Houdt JKJ (2009) Matrilinear phylogeography and demographical patterns of Rutilus rutilus: implications for taxonomy and conservation. Journal of fish biology, 75, 332-353.

Librado P, Rozas J (2009) DnaSP v5: a software for comprehensive analysis of DNA polymorphism data. Bioinformatics, 25, 1451-1452.

Luikart G, Cornuet J-M (2008) Empirical Evaluation of a Test for Identifying Recently Bottlenecked Populations from Allele Frequency Data. Conservation biology: the journal of the Society for Conservation Biology, 12.

Lusk S, Hanel L, Luskova V (2004) Red List of the ichthyofauna of the Czech Republic: Development and present status. Folia Zoologica, 53, 215-226.

Lusk S, Lusková, V, Hanel L (2010) Alien fish species in the Czech Republic and their impact on the native fish fauna. Folia Zoology, 59, 57-72. 
Mezhzherin SV, Kokodii SV, Kulish AV, Verlatii DB, Fedorenko LV (2012) Hybridization of crucian carp Carassius carassius (Linnaeus, 1758) in Ukrainian reservoirs and the genetic structure of hybrids. Cytology and genetics, 46, 28-35.

Miller MR, Dunham JP, Amores A, Cresko WA, Johnson EA (2006) Rapid and cost-effective polymorphism identification and genotyping using restriction site associated DNA (RAD) markers. Genome research, 17, 240-248.

Moore A, Russell IC, Potter ECE (1990) The effects of intraperitoneally implanted dummy acoustic transmitters on the behaviour and physiology of juvenile Atlantic salmon, Salmo salar L. Journal of fish biology, 37, 713-721.

Morin PA, Luikart G, Wayne RK, the SNP workshop group (2004) SNPs in ecology, evolution and conservation. Trends in ecology \& evolution, 19, 208-216.

Morin PA, Pease VL, Hancock BL et al. (2010) Characterization of 42 single nucleotide polymorphism (SNP) markers for the bowhead whale (Balaena mysticetus) for use in discriminating populations. Marine Mammal Science, 26, 716-732.

Mrakovčić M, Buj I, Mustafić P, Ćaleta M, Zanella D (2007) Croatian Red List: Freshwater fish. Department of Zoology, Faculty of Science, Zagreb.

Navodaru I, Buijse AD, Staras M (2002) Effects of Hydrology and Water Quality on the Fish Community in Danube Delta Lakes. International review of hydrobiology, 87, 329-348.

Nei M (1987) Molecular evolutionary genetics.

Nesbø CL, Fossheim T, Vøllestad LA, Jakobsen KS (1999) Genetic divergence and phylogeographic relationships among European perch (Perca fluviatilis) populations reflect glacial refugia and postglacial colonization. Molecular ecology, 8, 1387-1404.

Van Oosterhout C, Hutchinson WF, Wills DPM, Shipley P (2004) micro-checker: software for identifying and correcting genotyping errors in microsatellite data. Molecular ecology notes, $\mathbf{4}$, $535-538$.

Peery MZ, Kirby R, Reid BN et al. (2012) Reliability of genetic bottleneck tests for detecting recent population declines. Molecular ecology, 21, 3403-3418.

Petit RJ, El Mousadik A, Pons O (1998) Identifying Populations for Conservation on the Basis of Genetic Markers. Conservation biology: the journal of the Society for Conservation Biology, 12, 844-855.

R Core Team (2013) $R$ : a language and environment for statistical computing. ISBN 3-900051-070, Vienna, Austria.

Ramachandran S, Deshpande O, Roseman CC et al. (2005) Support from the relationship of genetic and geographic distance in human populations for a serial founder effect originating in Africa. Proceedings of the National Academy of Sciences of the United States of America, 102, 1594215947. 
Rasmussen H (1959) Fish ponds and fish rearing. In: Kulturhistoriskt lexikon för nordisk medeltid, pp. 307-309.

Reyjol Y, Hugueny B, Pont D et al. (2006) Patterns in species richness and endemism of European freshwater fish. Global ecology and biogeography, 65-75.

Rylková K, Kalous L, Bohlen J, Lamatsch DK, Petrtýl M (2013) Phylogeny and biogeographic history of the cyprinid fish genus Carassius (Teleostei: Cyprinidae) with focus on natural and anthropogenic arrivals in Europe. Aquaculture , 380-383, 13-20.

Salzburger W, Brandstätter A, Gilles A et al. (2003) Phylogeography of the vairone (Leuciscus souffia, Risso 1826) in Central Europe. Molecular ecology, 12, 2371-2386.

Savini D, Occhipinti-Ambrogi A, Marchini A et al. (2010) The top 27 animal alien species introduced into Europe for aquaculture and related activities. Journal of applied ichthyology, 26, 17.

Sayer CD, Copp GH, Emson D et al. (2011) Towards the conservation of crucian carp Carassius carassius: understanding the extent and causes of decline within part of its native English range. Journal of fish biology, 79, 1608-1624.

Schwartz MK, McKelvey KS (2009) Why sampling scheme matters: the effect of sampling scheme on landscape genetic results. Conservation genetics , 10, 441-452.

Simic, V, Simic S, Cirkovic M, Pantovic N (2009) Preliminary red list of the fishes of Serbia. COMBAFF-First Conference on Conservation and Management of Balkan Freshwater Fishes.

Simon A, Gozlan RE, Robert Britton J, van Oosterhout C, Hänfling B (2014) Human induced stepping-stone colonisation of an admixed founder population: the spread of topmouth gudgeon (Pseudorasbora parva) in Europe. Aquatic sciences, 77, 17-25.

Svanberg I, Bonow M, Olsén H (2013) Fish ponds in Scania, and Linnaeus's attempt promote aquaculture in Sweden. In: Svenska Linnésällskapets årsskrift (eds David B, Gunnar D), pp. 85100. Svenska Linnésällskapet, Uppsala.

Svärdson G (1998) Plostglacial dispersal and reticulate evolution of Nordic Coregonids. Nordic journal of freshwater research, 74, 3-32.

Takada M, Tachihara K, Kon T et al. (2010) Biogeography and evolution of the Carassius auratuscomplex in East Asia. BMC evolutionary biology, 10, 7.

Tamura K, Stecher G, Peterson D, Filipski A, Kumar S (2013) MEGA6: Molecular Evolutionary Genetics Analysis version 6.0. Molecular biology and evolution, 30, 2725-2729.

Tarkan AS, Cucherousset J, Zięba G, Godard MJ, Copp GH (2010) Growth and reproduction of introduced goldfish Carassius auratus in small ponds of southeast England with and without native crucian carp Carassius carassius. Zeitschrift fur angewandte Ichthyologie = Journal of applied ichthyology, 26, 102-108. 
Tavaré S (1986) Some probabilistic and statistical problems in the analysis of DNA sequences. In: Lectures in mathematics in the life sciences (ed Miura RM), pp. 57-86. American Mathematical Society, Providence, RI.

Urho L, Lehtonen H Fish species in Finland.

Weir B, Cockerham C (1984) Estimating F-statistics for the analysis of population structure. Evolution; international journal of organic evolution.

Wheeler A (2000) Status of the crucian carp, Carassius carassius (L.), in the UK. Fisheries management and ecology, 7, 315-322.

Wolfram G, Mikschi E (2007) Rote Liste der Fische (Pisces) Österreichs. In: Rote Liste gefährdeter Tiere Österreichs, Teil 2. Grüne Reihe des Lebensministeriums Band 14/2. (ed Zulka K), pp. 61198. Böhlau-Verlag, Wien, Köln, Weimar.

Wouters J, Janson S, Lusková V, Olsén KH (2012) Molecular identification of hybrids of the invasive gibel carp Carassius auratus gibelio and crucian carp Carassius carassius in Swedish waters. Journal of fish biology, 80, 2595-2604.

Xu P, Zhang X, Wang X et al. (2014) Genome sequence and genetic diversity of the common carp, Cyprinus carpio. Nature genetics. 


\section{Supplementary materials}

\section{Detecting hybrids}

\section{Methods}

In total we acquired tissue samples of 1078 Fish during sampling for this study. All of which were first genotyped using multiplex 1 (Supplementary table 1) which contained the 6 species diagnostic microsatellite loci. These data were then analysed using the NewHybrids v. 1.1 (Anderson \& Thompson 2002) software package in order to determine whether each fish was C. carassius, C. a. auratus, C. a. Gibelio or a hybrid between any of these species.

NewHybrids uses allele frequencies to give a likelihood probability that an individual belongs to one species or another, or if the individual one of several hybrid classes (F1, F2 or backcross). Data from 20 C. carassius samples, which were confidently identified as pure from both morphology and genotypes, and were not sympatric with non-native species, were included in each analysis as baseline data. Priors were then added to the analyses specifying that these individuals were indeed pure in order to give the software more power with which to assess allele frequencies associated with $C$. carassius. To be sure to account for allele frequency differences between different geographic regions, only pure individuals from regions neighbouring the hybrid population were used. Individuals which had more than a 25\% chance of being an F1 hybrid, F2 hybrid, or a backcross were removed from population structure analyses and were not genotyped at the additional 7 microsatellite loci (Multiplexes 2.1 and 2.2, Supplementary table 1).

\section{Results}

Of the 1087 genotyped fish from 58 populations, 942 individuals across 55 populations (86.7\%) were identified as pure crucian using the first set of 6 species diagnostic loci in NewHybrids analyses. 19(1.8\%) from 2 different populations were identified as C. a. auratus, 15 fish (1.4\%) from 4 populations were identified as. C. a. gibelio and 10 fish $(0.93 \%)$ from two populations were identified as C. carpio. NewHybrids identified 60(5.5\%) C. carassius x C. a. auratus hybrids, 25(2.2\%) C. carassius x C. a. gibelio hybrids, and 16(1.5\%) C. carassius x C. carpio hybrids. Of the 942 fish identified as pure C. carassius, 848 in 49 populations existed in sites where hybrids or non-native species were not detected by microsatellite genotyping. To safeguard against cryptic introgression which may produce erroneous results only these 848 pure $C$. carassius were used for the main phylogeographic analyses and tests of the status of $C$. carassius in England. 


\section{DAPC \& Running parameters}

\section{Methods}

Population structure was examined using Discriminant Analyses of Principal Components (DAPC, (Jombart et al. 2010)) in adegenet. Similar to the more commonly used program, STRUCTURE (Pritchard et al. 2000), DAPC is an individual-based approach that uses Principal Components Analysis (PCA) to transform population genetic data and Discriminant Analysis (DA) to identify clusters. The number of clusters is assessed using the K-means method, which is also used in STRUCTURE (Pritchard et al. 2000). Unlike STRUCTURE, DAPC does not assume underlying population genetics models such as Hardy-Weinberg Equilibrium (Jombart et al. 2010) and is therefore more suitable for analysing $\mathrm{C}$. carassius since populations are often bottlenecked (Hänfling et al. 2005). An additional benefit of DAPC is that it maximizes between-group variation, while minimizing variation within groups, allowing for optimal discrimination of betweenpopulation structure (Jombart et al. 2010).

\section{Results}

For the full microsatellite dataset (M1), BIC scores indicated that between 11 and 19 genetic clusters (Supplementary Figure 5) would be an appropriate model of the variation in the data. We therefore chose 11 clusters to use in the discriminant analysis, retaining 8 principal components as recommended by the spline interpolation a-scores (Supplementary Figure 5c) and we kept 2 linear discriminants for plotting (Figure 1b).

Three major lineages were found, one located in the Danube, one in the Don, and one spread across northern Europe. However the large amount of diveregence between them masked the population structure present in northern Europe. We therefore subsetted the data, separating NEU populations from RUS1, GER3, GER4, CZE1 (and SWE9, which was an outlier within NEU, Figure 1b) and reanalysed them with DAPC in order to better infer fine population structure between them.

For the RADseq dataset, BIC scores suggested between 9 and 14 genetic clusters, similar to the range inferred in the microsatellite data, we therefore chose 9 clusters to take forward in the analysis. As recommended by spline interpolation, we retained 7 principal components and we kept 2 of the linear discriminants from the subsequent discriminant analysis 


\section{Assessment of spatial uniformity of sampling locations}

\section{Methods}

In order to assess the geographic uniformity of the sampling regimes in each data subset, we used two measures of spatial patterns. The nearest neighbour distance distribution function $(\mathrm{G})$, measures the distance of each sampling location to its nearest neighbour (Ripley 1991). The L-function is a transformation (for ease of interpretation) of Ripley's K-function (Ripley 1991), which measures the number of sampling locations within a given radius from each point. $\mathrm{K}$ has the advantage of assessing the uniformity of the sampling regime over multiple scales, as opposed to only measuring distances between closest neighbours as with $\mathrm{G}$. In both cases, the estimates of $\mathrm{G}$ or $\mathrm{K}$ from our sampling locations were compared against random poisson distributions, which would represent uniformly spaced sampling locations. 5\% and 95\% confidence thresholds for these poisson distributions were also calculated to allow us to determine whether our sampling regimes significantly deviated from random ( $\mathrm{p}<0.05$ ). These calculations were performed using the Gest and Lest functions (for G and L respectively) in the package "spatstats" in R (Baddeley \& Turner 2005)

\section{Results}

Both methods used for the assessment of geographic uniformity of sampling locations shows that the M1 dataset locations are more patchily distributed than those of the M2, M3 and RAD datasets (Supplementary Figure 10).

\section{Additional discussion}

\section{Population structure in northwest Europe}

An intriguing result lies in the genetic similarity between populations in England with those in Belgium and Germany. C. carassius has been designated as native to England, however this status has been contentious in the past (Maitland 1972). Under the assumption that it is native, and considering the observed diversity and divergence times between populations across mainland Europe, we would expect to see stronger population structure between English and continental Europe, which have been separated for approximately 7800 years (Coles 2000). Given the observed diversity between populations across mainland Europe, which, according to DIYABC analysis, has arisen relatively recently. Clearly further examination of this issue is warranted and molecular data would be a value addition to the current evidence, which is predominantly anecdotal. 
Supplementary table 1 . Microsatellite loci used, grouped by their combinations in multiplex reactions. Multiplex primer mix ratios for PCR were chosen so as to give even peak strengths when analysing PCR products. Allele size ranges are those present in C. carassius for all 43 putatively pure crucian populations.

\begin{tabular}{lccccccc} 
Locus & Multiplex \# & $\begin{array}{c}\text { Primer mix } \\
\text { Ratios* }\end{array}$ & \# Alleles & Allele size range & Ho & $\begin{array}{c}\text { GenBank } \\
\text { Accession } \\
\text { no. }\end{array}$ & Reference \\
\hline GF1 & 1 & 0.1 & 1 & 299 & 0 & U35614 & Zheng et al. 1995 \\
GF17 & 1 & 0.1 & 2 & $182-186$ & 0.024 & U35616 & Zheng et al. 1995 \\
GF29 & 1 & 0.2 & 8 & $191-226$ & 0.348 & U35618 & Zheng et al. 1995 \\
J7 & 1 & 0.07 & 10 & $202-228$ & 0.109 & AY115095 & Yue \& Orban 2002 \\
MFW2 & 1 & 0.1 & 1 & 161 & 0 & - & Croojimans et al. 1997 \\
Ca07 & 1 & 0.2 & 9 & $122-140$ & 0.286 & D85428 & Yue \& Orban 2004 \\
TE Buffer & 1 & 0.23 & & & & & \\
\hline J69 & 2.1 & 0.4 & 14 & $213-241$ & 0.404 & AY115106 & Yue \& Orban 2002 \\
HJLY17 & 2.1 & 0.1 & 9 & $152-168$ & 0.223 & DQ378986 & Zhi-Ying et al. 2006 \\
HJLY35 & 2.1 & 0.1 & 18 & $261-307$ & 0.377 & DQ403242 & Zhi-Ying et al. 2006 \\
TE Buffer & 2.1 & 0.4 & & & & & \\
\hline J20 & 2.2 & 0.2 & 9 & $171-218$ & 0.149 & AY115099 & Yue \& Orban 2002 \\
J58 & 2.2 & 0.1 & 14 & $119-147$ & 0.398 & - & Yue \& Orban 2002 \\
MFW7 & 2.2 & 0.35 & 25 & $160-206$ & 0.464 & - & Croojimans et al. 1997 \\
MFW17 & 2.2 & 0.35 & 26 & $185-262$ & 0.41 & - & Croojimans et al. 1997
\end{tabular}

* All primers used at 10mM per ul concentration, diluted in ddH20 from 100mM per ul stock 
bioRxiv preprint doi: https://doi.org/10.1101/025973; this version posted September 2, 2015. The copyright holder for this preprint (which was not certified by peer review) is the author/funder. All rights reserved. No reuse allowed without permission.

Supplementary table 2. Haplotype memberships for 101 Cytochrome B sequences used in Fig. 2. Back to text.

\begin{tabular}{|c|c|c|c|c|}
\hline & Haplotype & $\mathbf{N}$ & $\begin{array}{c}\text { Drainage } \\
\text { (n populations) }\end{array}$ & $\begin{array}{l}\text { Sample } \\
\text { sequence }\end{array}$ \\
\hline \multirow{13}{*}{ 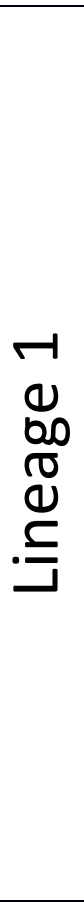 } & Hap 1 & 3 & Baltic & FIN5 1-3 \\
\hline & Hap 2 & 1 & Baltic & EST1 2 \\
\hline & Hap 3 & 49 & $\begin{array}{l}\text { Elbe(2), Baltic(24), } \\
\text { Scheldt(1), } \\
\text { Rhine(2), North } \\
\text { sea(2), Vistula(6), } \\
\text { Volga(4), Don(3), } \\
\text { Danube(1), } \\
\text { Hunte(4) }\end{array}$ & $\begin{array}{l}\text { GER1 1,3, EST1 1, 3, SWE6 } 1 \text {-3, BEL1 3, GER2 2, 3, GER4 2, NOR 1, 2, } \\
\text { SWE11 1-3, RUS2 2, RUS4 1, 3, FIN1 1-3, FIN4 1-3, POL4 1-3, RUS1 1-3, } \\
\text { SWE8 1-3, POL5 1-3, SWE4 1-3, RUS3 1, 3, 4, CZE2 1, GER6 1- 4, SWE14 1, SWE15 } \\
1\end{array}$ \\
\hline & Hap 4 & 1 & Volga & RUS2 1 \\
\hline & Hap 5 & 1 & Baltic & RUS4 2 \\
\hline & Hap 6 & 1 & Dnieper & BLS 3 \\
\hline & Hap 7 & 1 & Volga & RUS3 2 \\
\hline & Hap 8 & 3 & Baltic & SWE3 1-3 \\
\hline & Hap 9 & 2 & Baltic & SWE2 1,2 \\
\hline & Hap 10 & 1 & Baltic & SWE2 3 \\
\hline & Hap 11 & 3 & Baltic & SWE9 1-3 \\
\hline & Hap 12 & 13 & $\begin{array}{l}\text { UK(4), Rhine(1), } \\
\text { Baltic (2) }\end{array}$ & GBR7 1, GBR6 1-3, GBR8 1-3, NET 1, GER5 1-3, GBR12 1, 2 \\
\hline & Hap 13 & 3 & Baltic & FIN3 1-3 \\
\hline \multirow{9}{*}{ 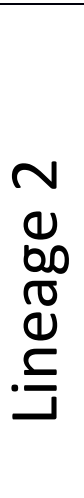 } & Hap 14 & 3 & Danube & $\begin{array}{l}\text { GER4 1, 2, AUS3 } \\
1\end{array}$ \\
\hline & Hap 15 & 3 & $\begin{array}{l}\text { Elbe(1), Rhine(1), } \\
\text { Danube(1) }\end{array}$ & GER1 2, GER2 1, AUS2 1 \\
\hline & Hap 16 & 1 & Danube & CZE1 1 \\
\hline & Hap 17 & 1 & Danube & CZE1 2 \\
\hline & Hap 18 & 1 & Danube & CZE1 3 \\
\hline & Hap 19 & 2 & Danube & HUN 1,2 \\
\hline & Hap 20 & 3 & Danube & GER3 1-3 \\
\hline & Hap 21 & 2 & Danube & AUS1 1, 2 \\
\hline & Hap 22 & 2 & Lahn & GER7 1, 2 \\
\hline
\end{tabular}


Supplementary table 3. Pairwise FST values calculated using the M1 dataset. Back to text.

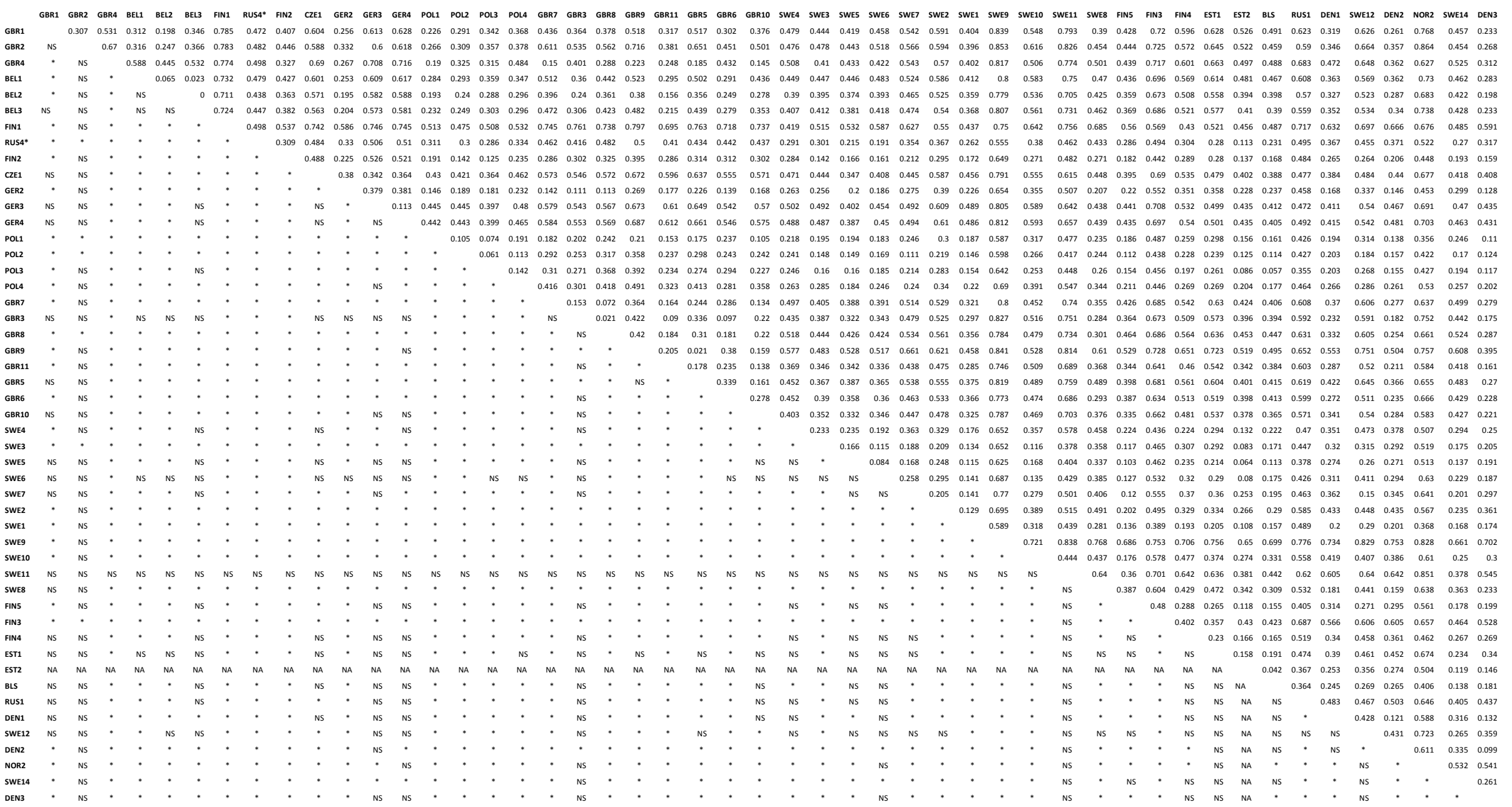


Supplementary table 4. Pairwise FST values calculated using the RADseq dataset. Back to text.

\begin{tabular}{|c|c|c|c|c|c|c|c|c|c|c|c|c|c|c|c|c|c|c|c|}
\hline & GBR8 & BEL1 & GBR4 & FIN3 & DEN1 & GBR7 & SWE12 & FIN4 & DEN2 & POL4 & RUS1 & SWE2 & SWE8 & SWE9 & SWE10 & NOR2 & POL3 & HUN2 & WEN \\
\hline GBR8 & & 0.34971 & 0.35695 & 0.49475 & 0.223897 & 0.35613 & 0.406544 & 0.295019 & 0.293628 & 0.211876 & 0.38775 & 0.308973 & 0.273693 & 0.412263 & 0.321365 & 0.650207 & 0.146766 & 0.61801 & 0.397239 \\
\hline BEL1 & & & 0.370425 & 0.390916 & 0.098308 & 0.381154 & 0.300836 & 0.225496 & 0.130398 & 0.152617 & 0.343954 & 0.22423 & 0.08032 & 0.326848 & 0.235947 & 0.522507 & 0.103445 & 0.597677 & 0.31111 \\
\hline GBR4 & & & & 0.513779 & 0.231153 & 0.195241 & 0.423664 & 0.302246 & 0.316185 & 0.218776 & 0.392539 & 0.314975 & 0.284155 & 0.422534 & 0.331921 & 0.698989 & 0.149208 & 0.620806 & 0.412409 \\
\hline FIN3 & & & & & 0.308284 & 0.517114 & 0.341754 & 0.198275 & 0.364426 & 0.222674 & 0.378729 & 0.27048 & 0.328488 & 0.331267 & 0.286862 & 0.562015 & 0.149991 & 0.614832 & 0.341565 \\
\hline DEN1 & & & & & & 0.244594 & 0.239562 & 0.194342 & 0.06762 & 0.136982 & 0.356985 & 0.182005 & 0.085513 & 0.266461 & 0.190793 & 0.362014 & 0.102429 & 0.602815 & 0.237037 \\
\hline GBR7 & & & & & & & 0.430574 & 0.31162 & 0.32391 & 0.229621 & 0.396753 & 0.319608 & 0.295939 & 0.433712 & 0.340292 & 0.692819 & 0.157339 & 0.621918 & 0.422803 \\
\hline SWE12 & & & & & & & & 0.209406 & 0.282835 & 0.173199 & 0.363912 & 0.198857 & 0.259513 & 0.303204 & 0.211775 & 0.459576 & 0.122381 & 0.606576 & 0.250115 \\
\hline FIN4 & & & & & & & & & 0.218225 & 0.142389 & 0.328888 & 0.154803 & 0.211809 & 0.203425 & 0.174944 & 0.316929 & 0.099233 & 0.586541 & 0.198636 \\
\hline DEN2 & & & & & & & & & & 0.153556 & 0.362177 & 0.212179 & 0.101801 & 0.307702 & 0.222051 & 0.459347 & 0.108029 & 0.60623 & 0.284015 \\
\hline POL4 & & & & & & & & & & & 0.321777 & 0.128672 & 0.150743 & 0.192186 & 0.138734 & 0.250273 & 0.073063 & 0.579543 & 0.161299 \\
\hline RUS1 & & & & & & & & & & & & 0.341129 & 0.358602 & 0.368371 & 0.349288 & 0.396194 & 0.278006 & 0.516158 & 0.358584 \\
\hline SWE2 & & & & & & & & & & & & & 0.19768 & 0.218326 & 0.145195 & 0.325228 & 0.094924 & 0.591579 & 0.151258 \\
\hline SWE8 & & & & & & & & & & & & & & 0.289356 & 0.208013 & 0.401551 & 0.110433 & 0.604134 & 0.262799 \\
\hline SWE9 & & & & & & & & & & & & & & & 0.257245 & 0.429544 & 0.136442 & 0.607715 & 0.29715 \\
\hline SWE10 & & & & & & & & & & & & & & & & 0.350951 & 0.100275 & 0.598136 & 0.184722 \\
\hline NOR2 & & & & & & & & & & & & & & & & & 0.165304 & 0.625602 & 0.426179 \\
\hline POL3 & & & & & & & & & & & & & & & & & & 0.547371 & 0.111018 \\
\hline HUN2 & & & & & & & & & & & & & & & & & & & 0.604399 \\
\hline
\end{tabular}


bioRxiv preprint doi: https://doi.org/10.1101/025973; this version posted September 2, 2015. The copyright holder for this preprint (which was not certified by peer review) is the author/funder. All rights reserved. No reuse allowed without permission.

Supplementary table 5. Genbank accession numbers for the mtDNA sequences used in this study. Back to text

\begin{tabular}{|c|c|}
\hline Sample code & Accession number \\
\hline FIN5_01 & KT630314 \\
\hline FIN5_02 & KT630315 \\
\hline FIN5_03 & KT630316 \\
\hline EST1_02 & KT630317 \\
\hline GER1_01 & KT630318 \\
\hline EST1_01 & KT630319 \\
\hline GER1_03 & KT630320 \\
\hline SWE6_01 & KT630321 \\
\hline SWE6_02 & KT630322 \\
\hline SWE6_03 & KT630323 \\
\hline BEL1_03 & KT630324 \\
\hline EST1_03 & KT630325 \\
\hline GER2_02 & KT630326 \\
\hline GER2_03 & KT630327 \\
\hline GER4_02 & KT630328 \\
\hline NOR1_01 & KT630329 \\
\hline NOR1_02 & KT630330 \\
\hline SWE11_01 & KT630331 \\
\hline SWE11_02 & KT630332 \\
\hline SWE11_03 & KT630333 \\
\hline RUS2_02 & KT630334 \\
\hline RUS4_01 & KT630335 \\
\hline RUS4_03 & KT630336 \\
\hline FIN1_01 & KT630337 \\
\hline FIN1_02 & KT630338 \\
\hline FIN1_03 & KT630339 \\
\hline FIN4_01 & KT630340 \\
\hline FIN4_02 & KT630341 \\
\hline FIN4_03 & KT630342 \\
\hline POL4_01 & KT630343 \\
\hline POL4_02 & KT630344 \\
\hline POL4_03 & KT630345 \\
\hline RUS1_01 & KT630346 \\
\hline RUS1_02 & KT630347 \\
\hline RUS1_03 & KT630348 \\
\hline SWE8_01 & KT630349 \\
\hline SWE8_02 & KT630350 \\
\hline SWE8_03 & KT630351 \\
\hline POL3_01 & KT630352 \\
\hline POL3_02 & KT630353 \\
\hline POL3_03 & KT630354 \\
\hline SWE4_01 & KT630355 \\
\hline SWE4_02 & KT630356 \\
\hline SWE4_03 & KT630357 \\
\hline RUS3_01 & KT630358 \\
\hline RUS3_03 & KT630359 \\
\hline RUS3_04 & KT630360 \\
\hline RUS2_01 & KT630361 \\
\hline RUS4_02 & KT630362 \\
\hline BLS_03 & KT630363 \\
\hline RUS3_02 & KT630364 \\
\hline SWE3_01 & KT630365 \\
\hline SWE3_02 & KT630366 \\
\hline SWE3_03 & KT630367 \\
\hline SWE2_01 & KT630368 \\
\hline SWE2_02 & KT630369 \\
\hline SWE2_03 & KT630370 \\
\hline SWE9_01 & KT630371 \\
\hline SWE9_02 & KT630372 \\
\hline SWE9_03 & KT630373 \\
\hline GBR7_01 & KT630374 \\
\hline GBR6_01 & KT630375 \\
\hline GBR8_01 & KT630376 \\
\hline GBR8_02 & KT630377 \\
\hline GBR8_03 & KT630378 \\
\hline GBR6_02 & KT630379 \\
\hline GBR6_03 & KT630380 \\
\hline CZE1_01 & KT630381 \\
\hline CZE1_02 & KT630382 \\
\hline CZE1_03 & KT630383 \\
\hline GER4_01 & KT630384 \\
\hline GER4_03 & KT630385 \\
\hline GER1_02 & KT630386 \\
\hline GER2_01 & KT630387 \\
\hline FIN3_01 & KT630388 \\
\hline FIN3_02 & KT630389 \\
\hline FIN3_03 & KT630390 \\
\hline HUN1_02 & KT630391 \\
\hline GER3_01 & КT630392 \\
\hline GER3_02 & KT630393 \\
\hline GER3_03 & KT630394 \\
\hline
\end{tabular}




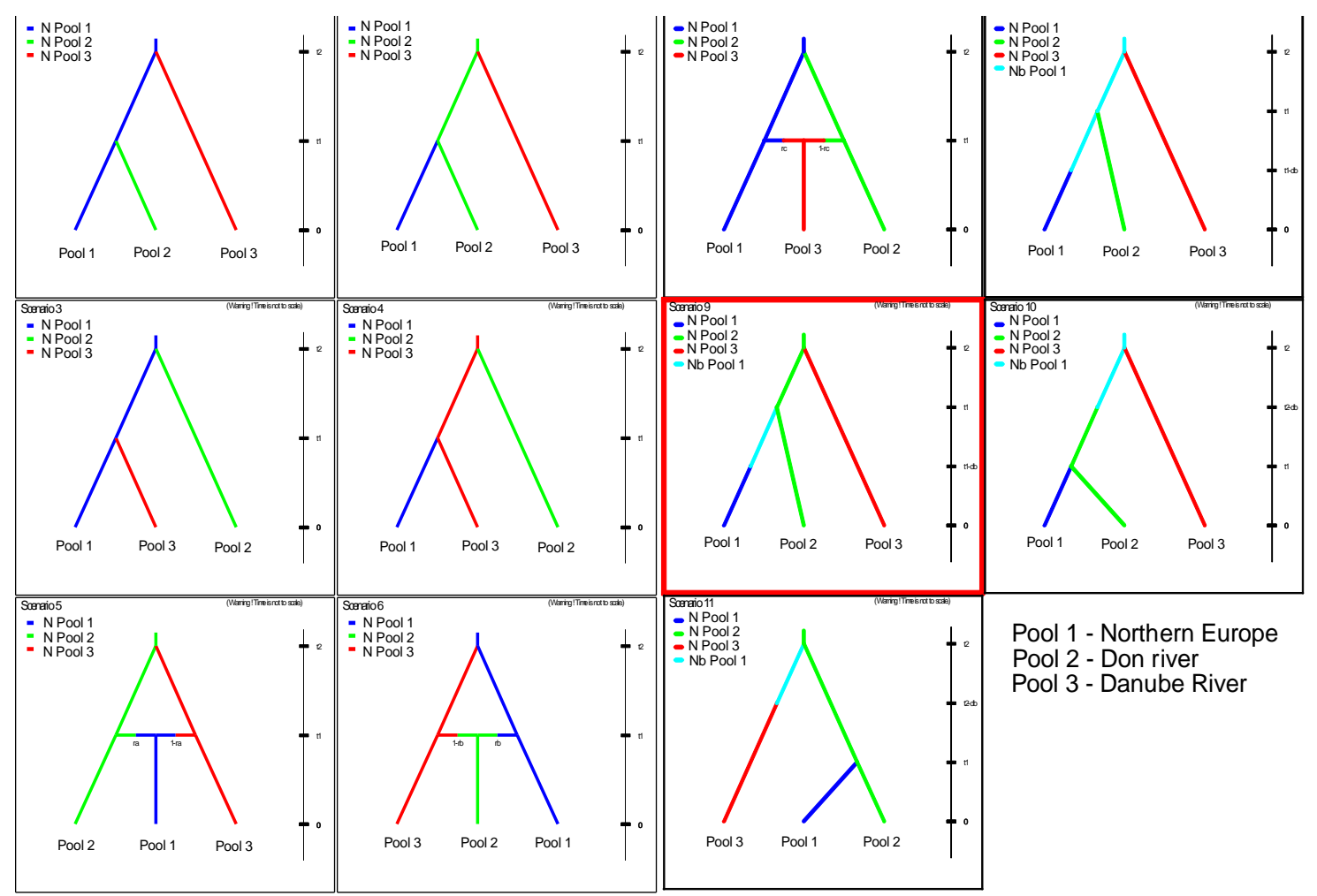

Supplementary Figure 1. DIYABC scenarios used in broad-scale analysis (Stage 1). See text for population poolings. See Table 3 for population poolings and prior parameter values. Back to text.
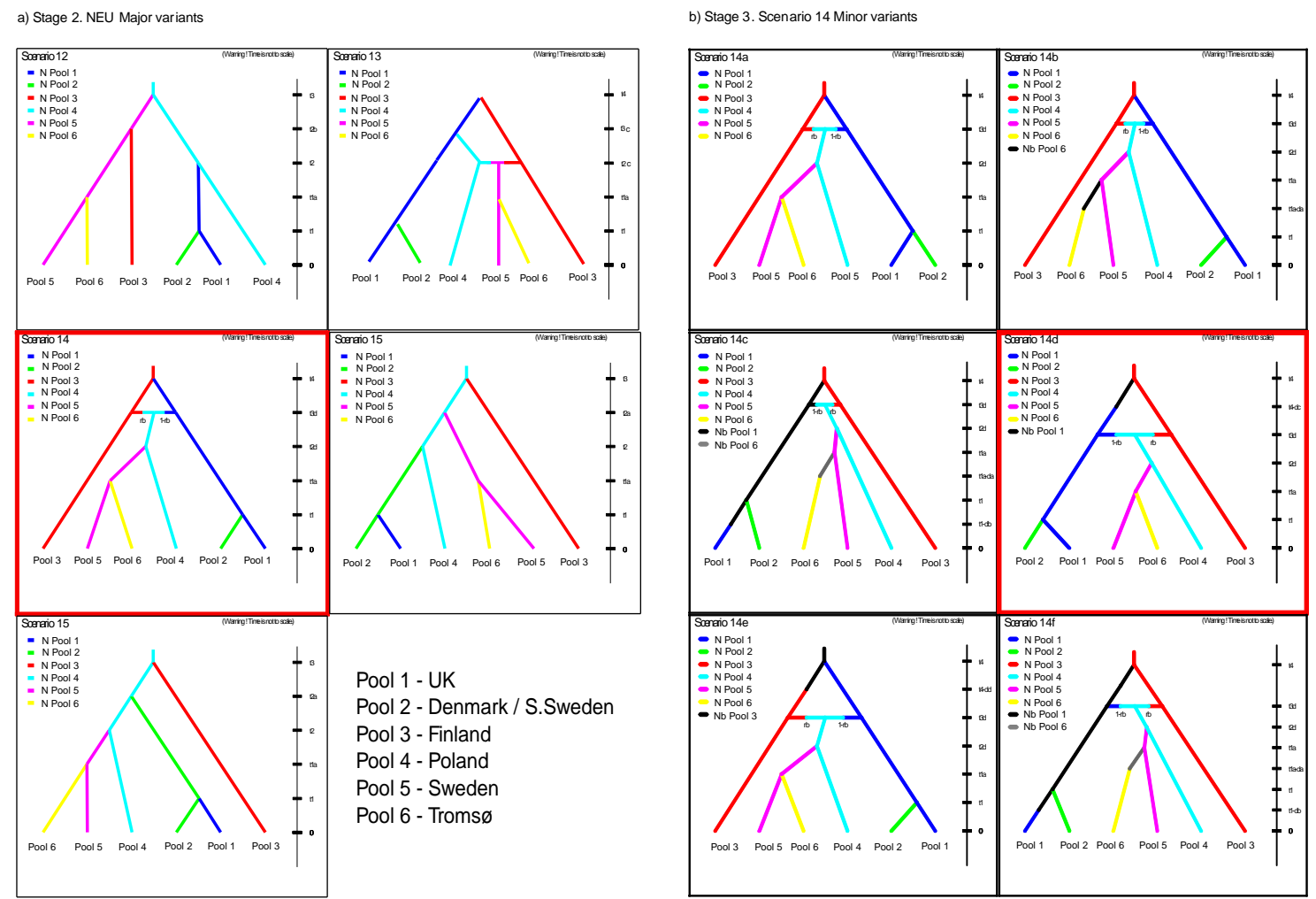

Supplementary Figure 2. All scenarios tested in stage 2 a) and stage 3 b) of DIYABC analysis. See Table 3 for population poolings and prior parameter values. $\underline{\text { Back to text. }}$ 

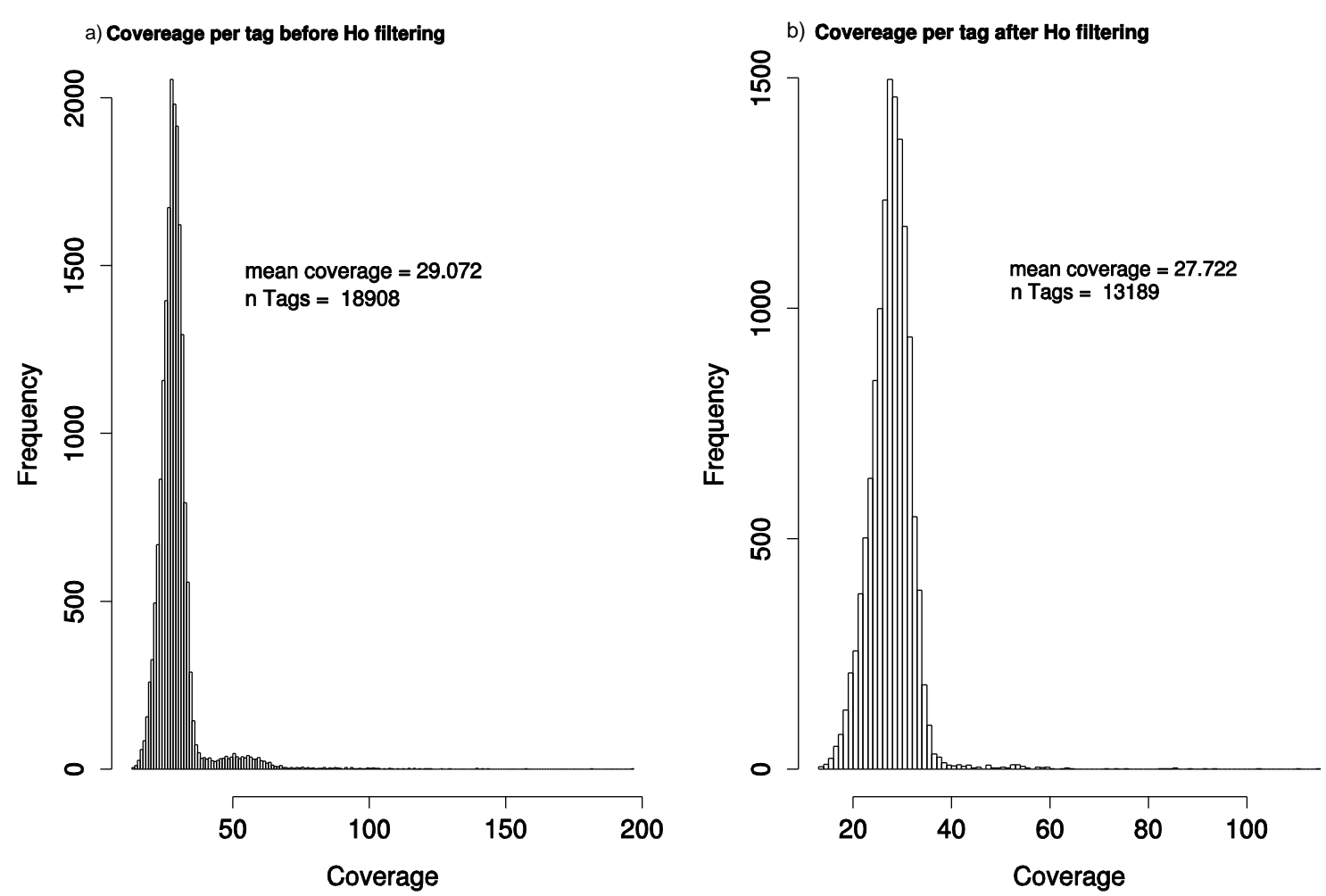

Supplementary Figure 3. Filtering out merged ohnologs. a) Distribution of SNP locus coverage prior to removing loci that had observed heterozygosity higher than 0.5 in one or more population. b) Distribution of locus coverage after filtering, showing a loss of many high coverage loci and a reduction in mean SNP coverage. Note the loss of loci with high coverage. Back to text
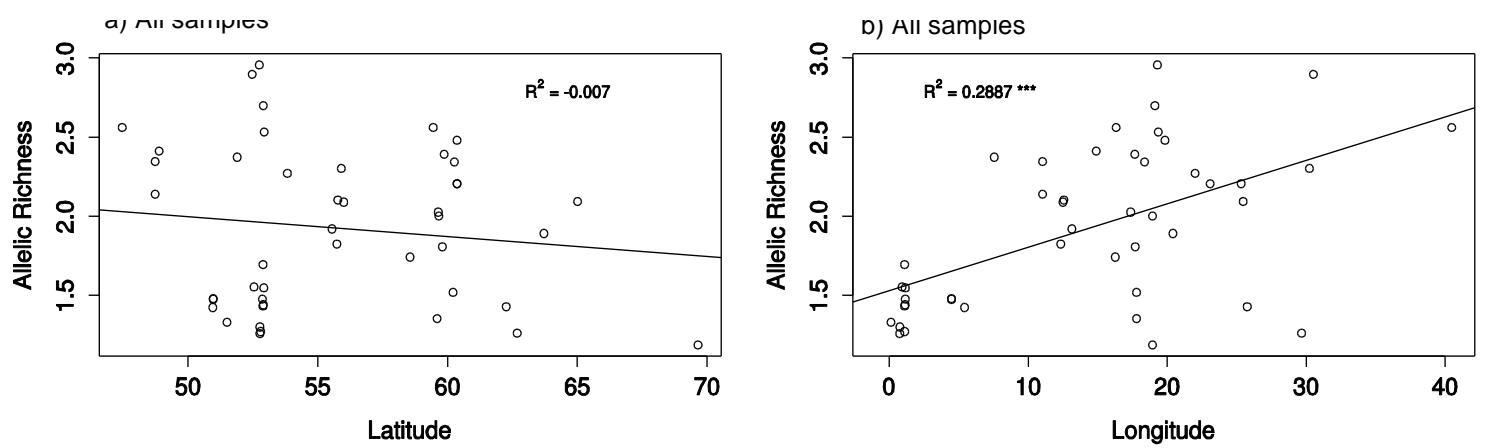

c) mtDNA Lineage 1 only
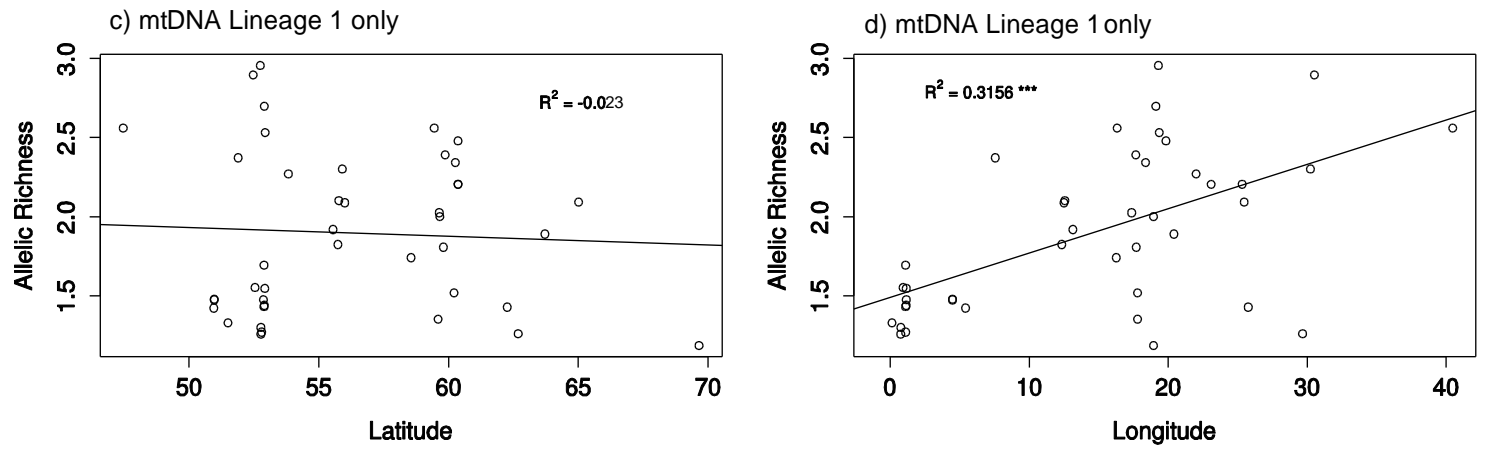

Supplementary Figure 4. Linear regressions for all samples a) Ar against latitude; b) Ar against longitude and for only samples in mtDNA lineage 1 c) Ar against latitude; d) Ar against longitude. Back to text. 

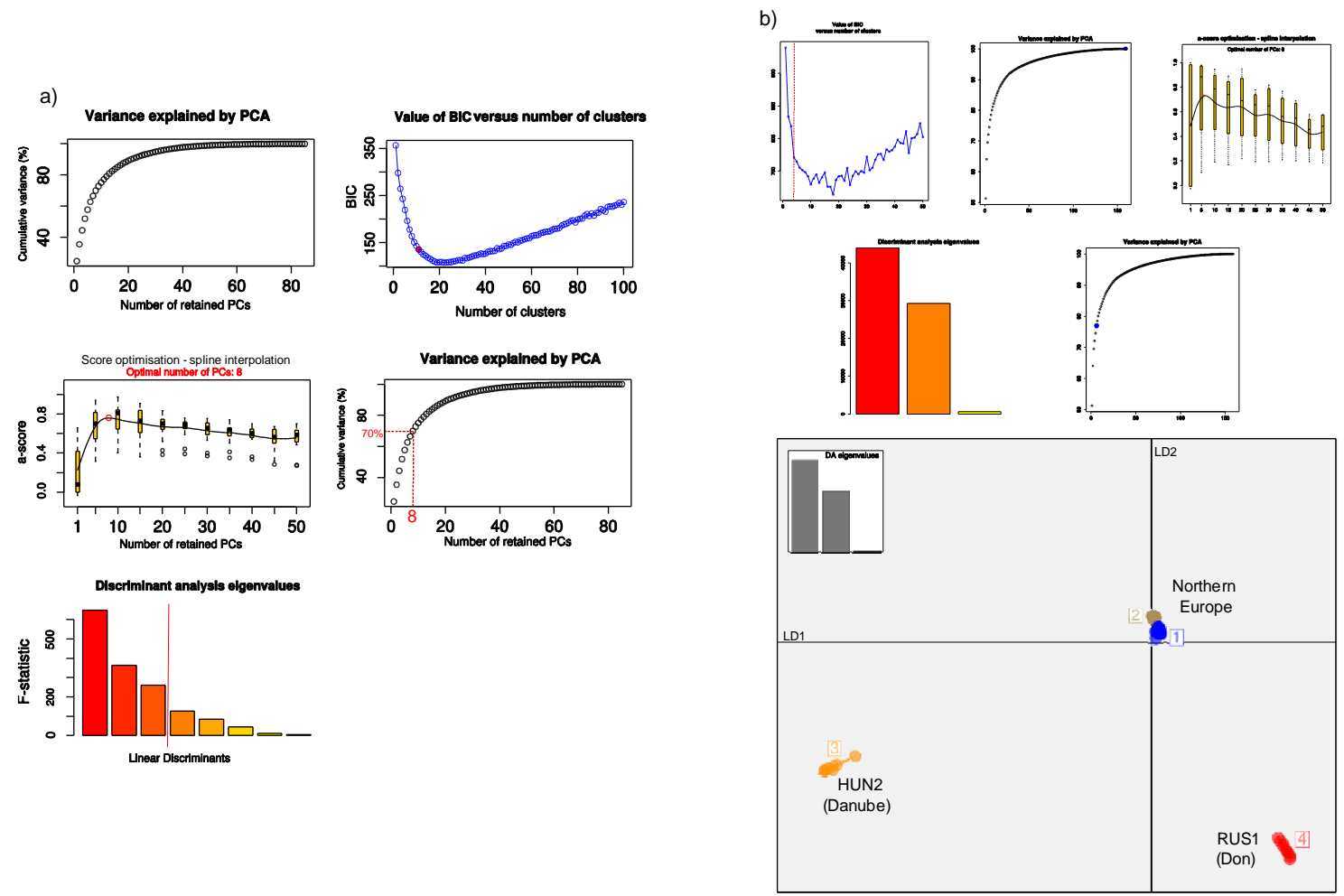

Supplementary Figure 5. DAPC analysis of a) full microsatellite dataset (Excluding NOR2); for results used in Fig. 1) and b) Full RADseq dataset. Back to text.

a) M1, Lineage 1 only (excluding NOR2)
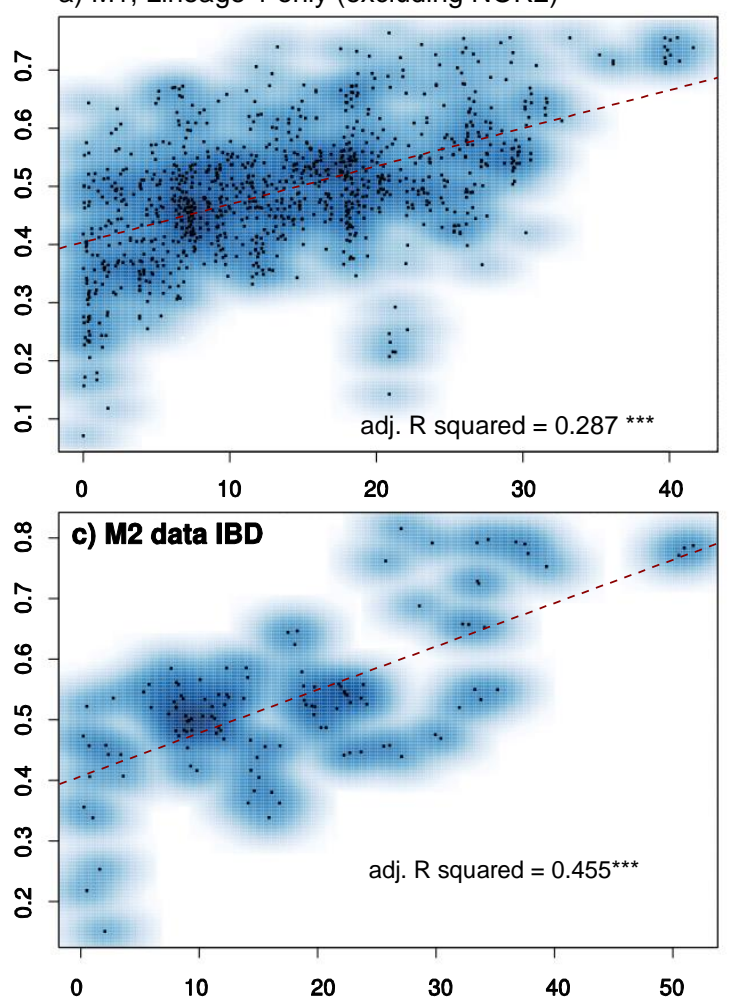

b) RADseq data IBD
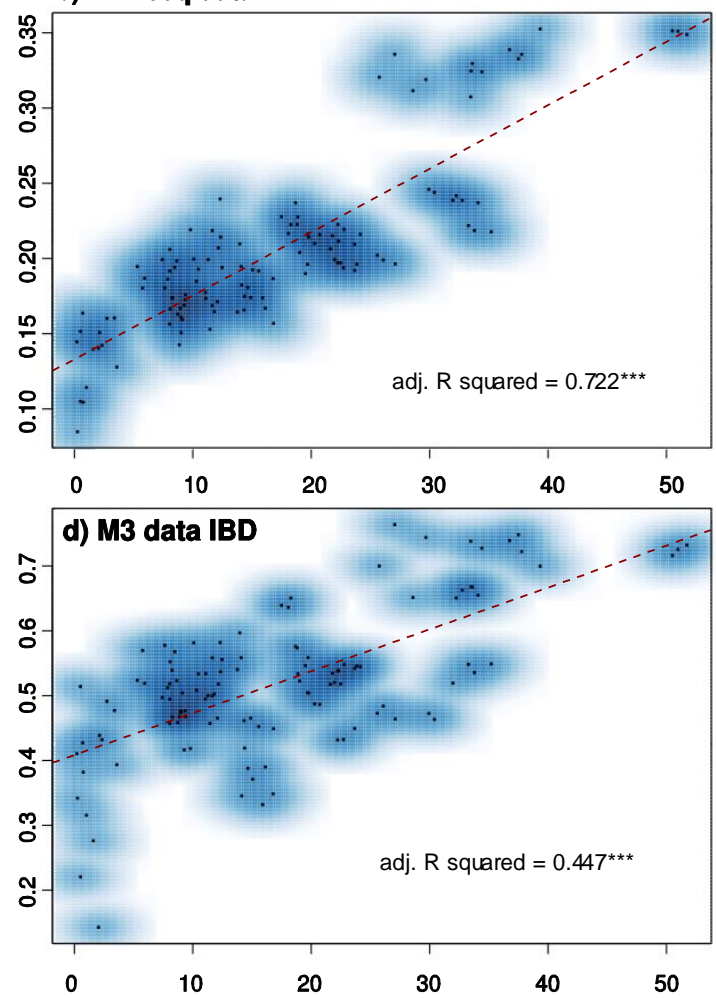

Supplementary Figure 6. Isolation by distance a) in M1 dataset for mtDNA lineage 1 only (excluding NOR2), b) Full RADseq dataset, c) M2 dataset and d) M3 dataset._Back to text. 
bioRxiv preprint doi: https://doi.org/10.1101/025973; this version posted September 2, 2015. The copyright holder for this preprint (which was not certified by peer review) is the author/funder. All rights reserved. No reuse allowed without permission.

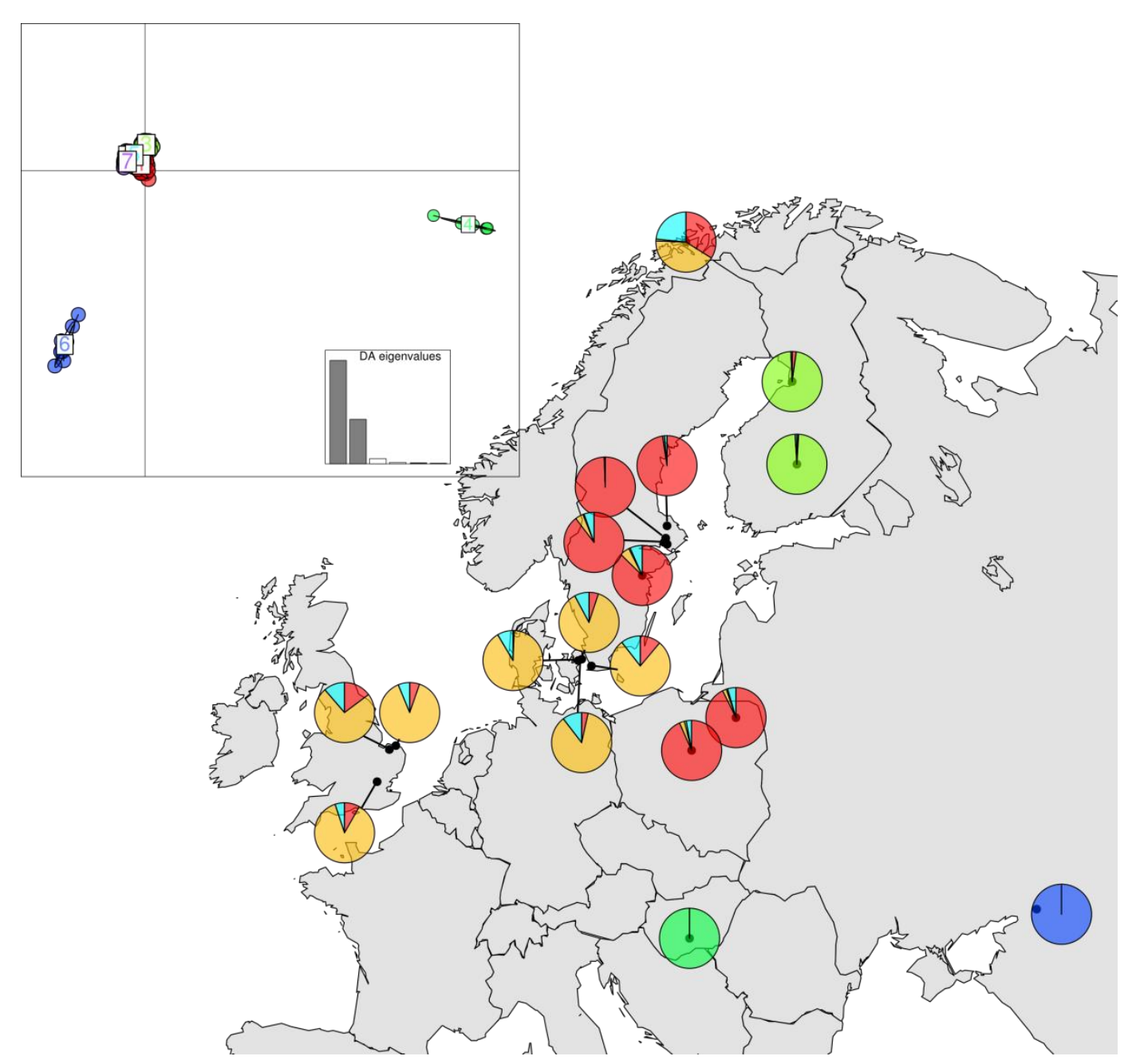

Supplementary Figure 7. DAPC scatter plot for the 100 SNP RADseq dataset used in the DIYABC analysis, showing the same population structure as inferred from the full RADseq dataset. Back to text. 
a)

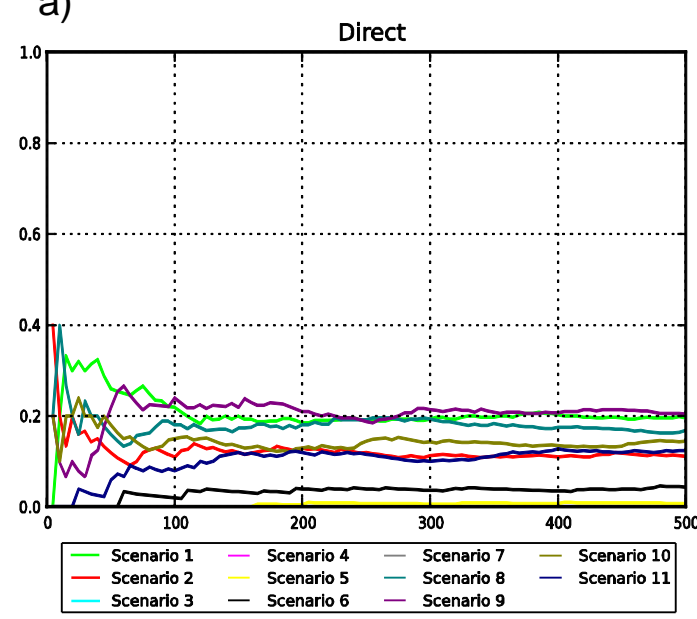

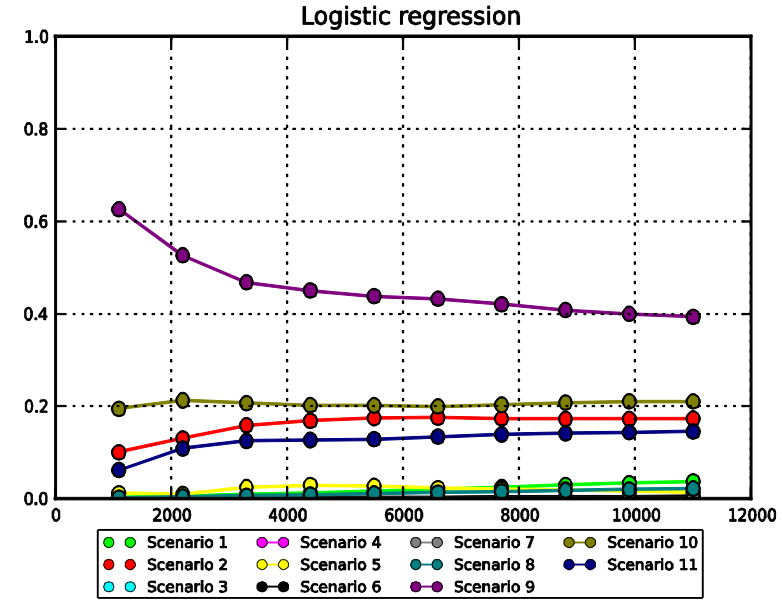

b)

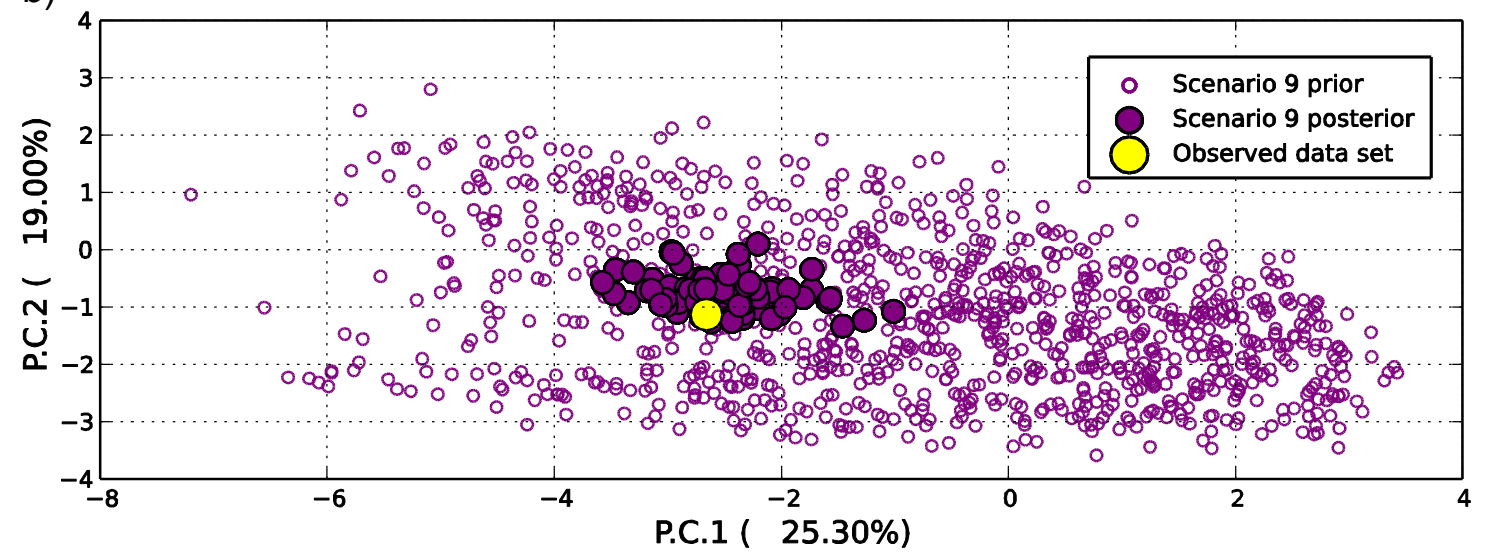

c)

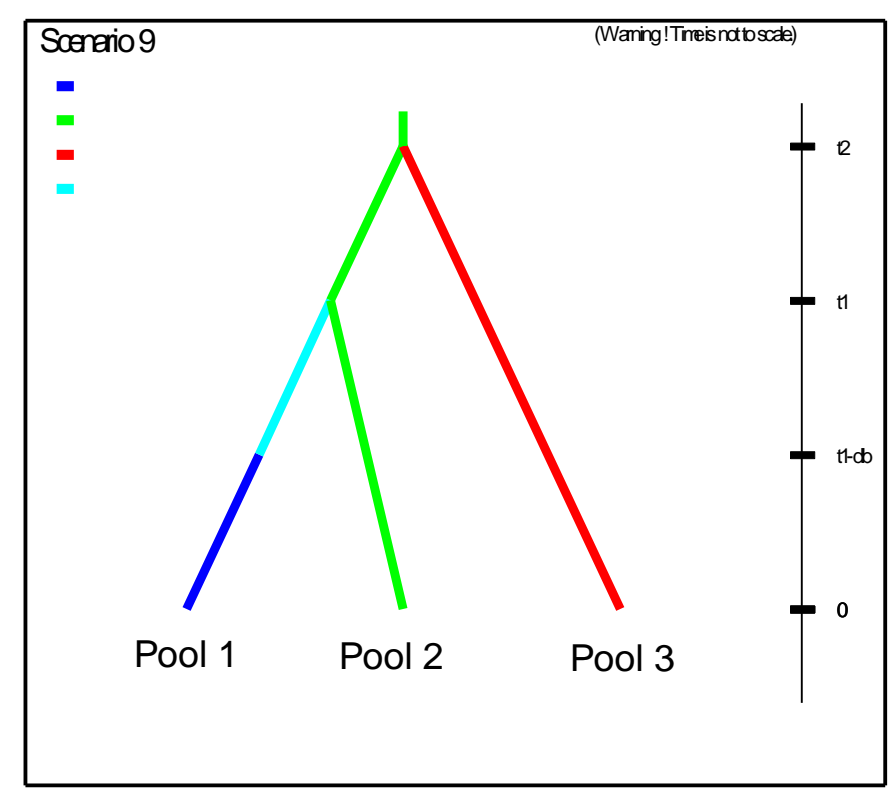

Supplementary Figure 8. Broad scale DIYABC analysis (Stage 1) results. a) Direct approact (left) and Logistic regression (right) showing support for scenario 9. b) Model checking for scenario 9, showing that the observed data fall well within the cloud of datasets simulated from the posterior parameter distribution. c) Scenario 9 schematic. Back to text. 
a) Stage 2. NEU major variants
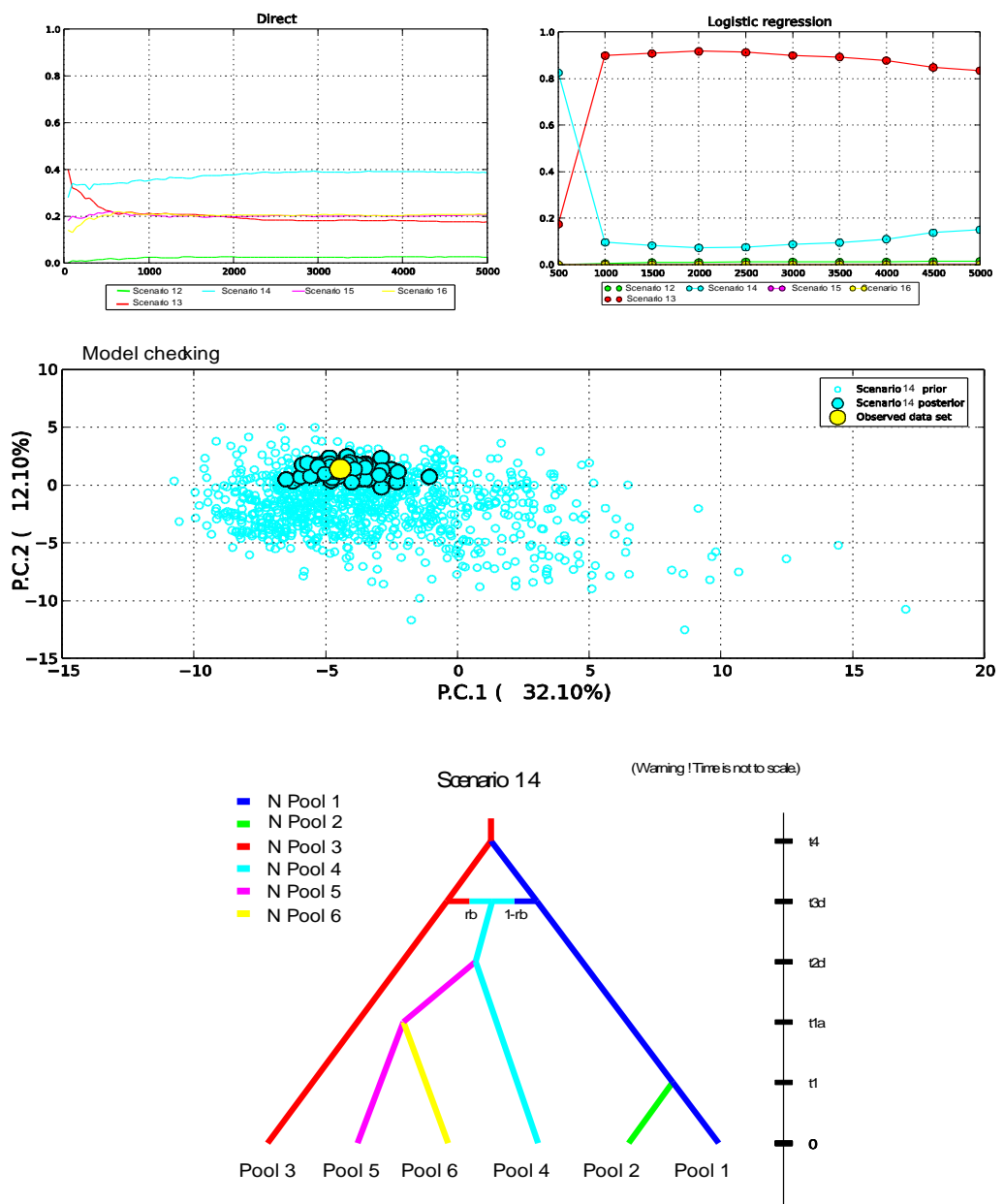

b) Stage 3. NEU minor variants
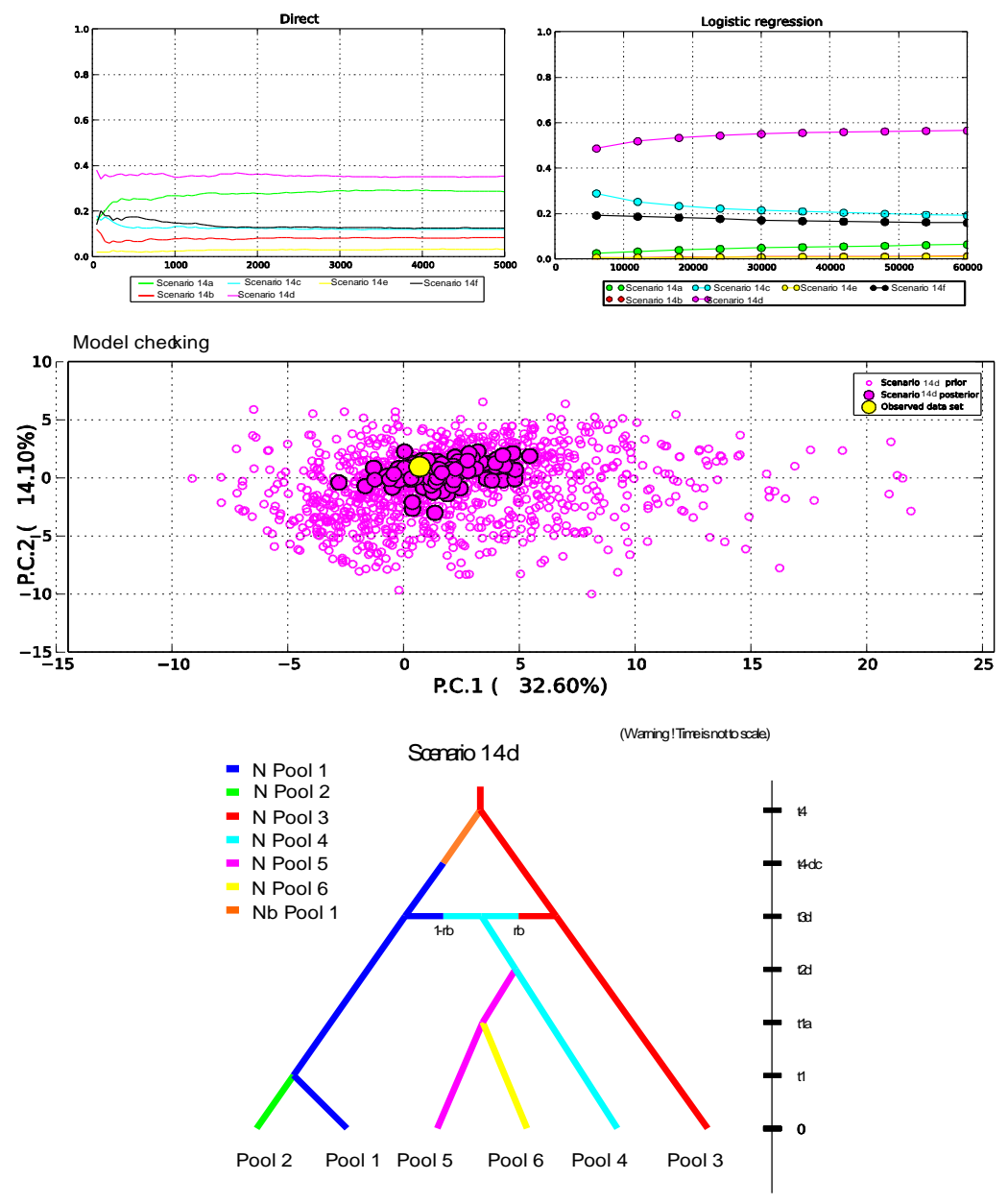

Supplementary Figure 9. Fine scale DIYABC analysis in northern Europe.. a) Stage 2 - major topological variants of scenarios. Direct approact (top left) and Logistic regression (top right) showing support for scenario 14 and 13 respectively. Model checking (Middle) for scenario 14 (bottom), showing that the observed data fall well within the cloud of datasets simulated from the posterior parameter distribution. Note the model checking placed the observed data outside of the cloud of posterior datasets for scenario 13. b) Stage 3 - Minor scenario variants of scenario 14 from stage 2. Direct approach (top left), logistic regression (top right) and model checking (middle) all support scenario $14 \mathrm{~d}$ (bottom). Back to text. 
a)

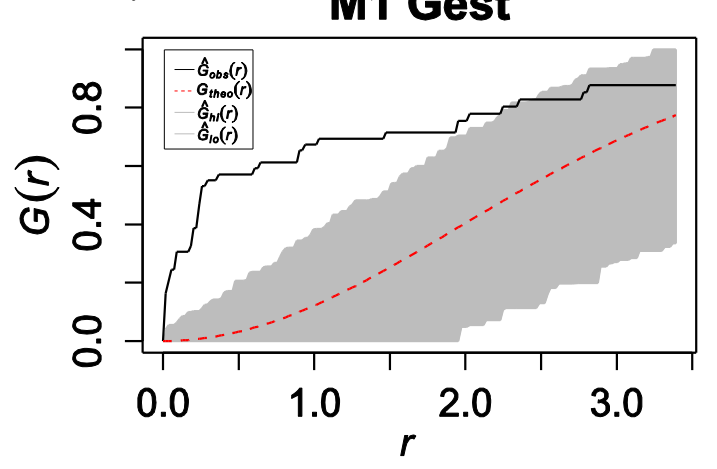

c)

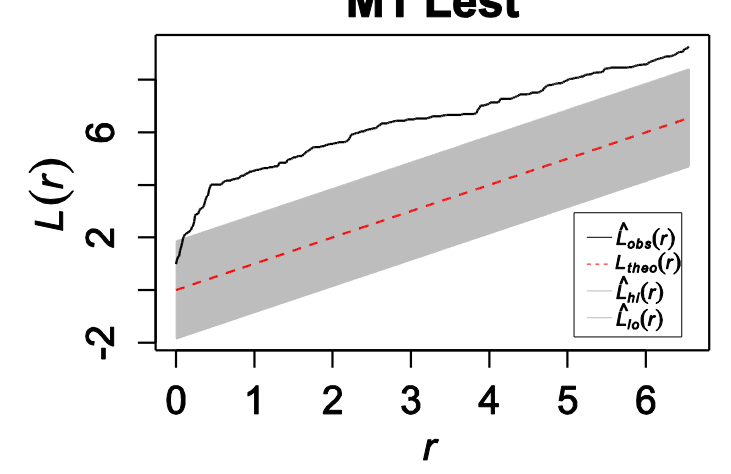

b)

M2 Gest

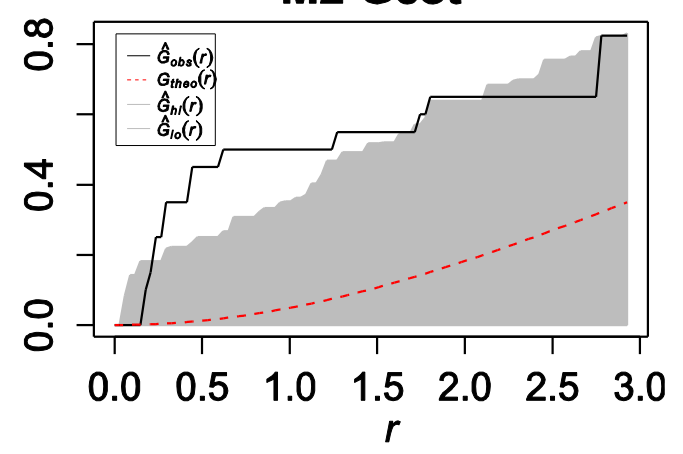

d)

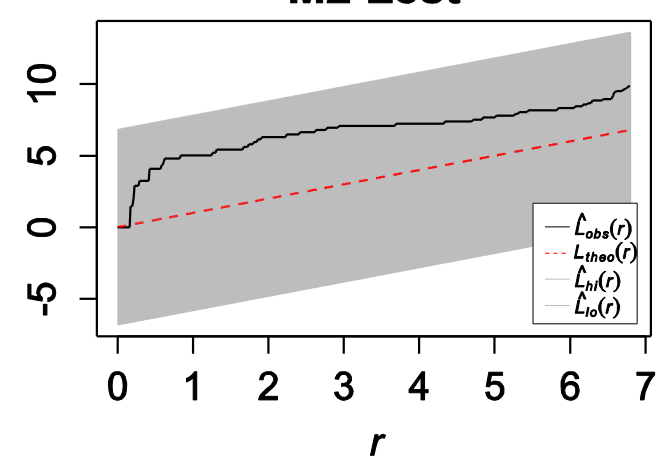

Supplementary Figure 10. Comparison of spatial patterns of uniformity in geographic sampling regimes of the full M1 dataset locations (a, c) and the sampling location subset used in M2, M3, and RAD datasets $(b, d)$. Estimates of $\mathrm{G}$ and $\mathrm{L}$ from true sampling locations are plotted using the black solid lines. Estimates of $\mathrm{G}$ and $\mathrm{L}$ from simulated locations based on random poisson distribution is represented by the red dashed line. Grey shaded areas are the $95 \%$ confidence intervals around the random estimates. Both the $\mathrm{G}$ and $\mathrm{L}$ function estimates show that there is more clustering of sampling locations in the M1 dataset than in the M2, M3 and RAD subsets. Back to text. 